Research Paper

\title{
Signal regulatory protein $\alpha$ associated with the progression of oral leukoplakia and oral squamous cell carcinoma regulates phenotype switch of macrophages
}

\author{
Xiaojing Ye ${ }^{1}$, Jing Zhang ${ }^{1,2}$, Rui Lu' ${ }^{1,2}$, Gang Zhou ${ }^{1,2}$ \\ ${ }^{1}$ The State Key Laboratory Breeding Base of Basic Science of Stomatology (Hubei-MOST) and Key Laboratory of Oral \\ Biomedicine Ministry of Education, School and Hospital of Stomatology, Wuhan University, Wuhan, P.R. China \\ ${ }^{2}$ Department of Oral Medicine, School and Hospital of Stomatology, Wuhan University, Wuhan, P.R. China \\ Correspondence to: Gang Zhou, email: gordonzhou@tom.com \\ Keywords: signal regulatory protein $\alpha$, macrophage, oral leukoplakia, oral squamous cell carcinoma \\ Received: May 29, $2016 \quad$ Accepted: September 24, $2016 \quad$ Published: October 25, 2016
}

\section{ABSTRACT}

Signal regulatory protein $\alpha(\mathrm{SIRP} \alpha)$ is a cell-surface protein expressed on macrophages that are regarded as an important component of the tumor microenvironment. The expression of SIRP $\alpha$ in oral leukoplakia (OLK) and oral squamous cell carcinoma (OSCC), and further explored the role of SIRP $\alpha$ on the phenotype, phagocytosis ability, migration, and invasion of macrophages in OSCC were investigated. The expression of SIRP $\alpha$ in OLK was higher than in OSCC, correlating with the expression of CD68 and CD163 on macrophages. After cultured with the conditioned media of oral cancer cells, the expression of SIRP $\alpha$ on THP-1 cells was decreased gradually. In co-culture system, macrophages were induced into M2 phenotype by oral cancer cells. Blockade of SIRP $\alpha$ inhibited phagocytosis ability and IL-6, TNF- $\alpha$ productions of macrophages. In addition, the proliferation, migration, and IL-10, TGF- $\beta$ productions of macrophages were upregulated after blockade of SIRP $\alpha$. Macrophages upregulated the expression of SIRP $\alpha$ and phagocytosis ability, and inhibited the migration and invasion when the activation of NF-KB was inhibited by pyrrolidine dithiocarbamate ammonium (PDTC). Hence, SIRP $\alpha$ might play an important role in the progression of OLK and oral cancer, and could be a pivotal therapeutic target in OSCC by regulating the phenotype of macrophages via targeting NF-кB.

\section{INTRODUCTION}

As one of the most common cancers in the world, oral squamous cell carcinoma (OSCC) is characterized by high cervical lymph node metastasis and poor prognosis $[1,2]$. The development from oral precancer to oral cancer in histopathology level may undergo epithelial hyperplasia, dysplasia, early invasive stage as well as lymph node metastasis [3]. Recently, the tumor microenvironment has been known as an important hallmark of cancer [4]. In tumor microenvironments, macrophages are characterized as a major inflammatory component of the stroma and affect many aspects of the tumor tissue [5].

Macrophages play important roles in linking innate with adaptive immunity and their capacity of immuneregulatory, possessing functions including phagocytosis, cytokine production, and antigen presentation [6].
Macrophages are often called tumor-associated macrophages (TAMs) in tumors and are considered as an important component of the tumor microenvironment, featuring remarkable diversity and plasticity [7]. M1 macrophages (classical activation) are mediated by interferon-gama (IFN- $\gamma$ ) and lipopolysaccharide (LPS), while M2 macrophages (alternative activation) are induced by interleukin (IL)-4, IL-10, and IL-13 [8]. M2 macrophages produce high levels of IL-10, express scavenger receptors, and exhibit tissue repair and anti-inflammatory functions [9, 10]. In contrast, M1 macrophages are potent killers of pathogens and tumor cells, generating pro-inflammatory cytokines and expressing high levels of MHC molecules [9].

Nuclear factor (NF)- $\kappa \mathrm{B}$ plays an important roles in inflammation and immunity, which is a generic term for a family of transcription factors [11]. Various studies 
have indicated that inhibition of NF- $\kappa \mathrm{B}$ activation helps to drive the tumor-promoting phenotype of TAMs [12, 13]. Macrophages are polarized to M2-like phenotype by malignant epithelial cells [14]. Positive correlation was found between macrophage infiltrated in the tumor stroma and OSCC with a higher histological grading [15]. $\mathrm{Ni}$ et al demonstrated that TAM also played a unique role in prognosis of patients with OSCC [16]. Besides, study found that the NF- $\kappa$ B pathway might involve in the induction of M2 phenotype macrophage polarization by OSCC cells [17]. In addition, macrophage polarization influences progression and survival of solid malignancies, including OSCC $[18,19]$.

Signal regulatory protein $\alpha(\operatorname{SIRP} \alpha)$ is a cell-surface protein mainly expressed on myeloid cells, including macrophages and dendritic cells [20]. SIRP $\alpha$ may play an important role in immune regulation because the extracellular region of SIRP $\alpha$ is heavily glycosylated and consists of three immunoglobin superfamily (IgSF) domains, which are similar to the $\mathrm{T}$ cell receptor (TCR) [21]. SIRP $\alpha$ can bind to either widely expressed transmembrane ligand CD47 or soluble ligands [21]. The expression of SIRP $\alpha$ and CD47 are varies during infection and malignancies, and they are involved in the pathogenesis of various tumor, such as melanoma, leukaemia, lung cancer $[22,23]$. Our previous study showed that CD47 was up-regulated in oral leukoplakia (OLK) and OSCC, suggesting cancer cells may evade phagocytosis of macrophages through the interaction of CD47 with $\operatorname{SIRP} \alpha$.

However, the profile of SIRP $\alpha$ expression in OLK and OSCC and the mechanism by $\operatorname{SIRP} \alpha$ regulating macrophages or oral cancer cells remain unclear. Thus, the aim of the current study was to investigate the distribution and the incidence of SIRP $\alpha$ on macrophages and the relation to clinicopathological factors. Moreover, this study explored the regulation of $\operatorname{SIRP} \alpha$ on cell phagocytosis, phenotype, proliferation, invasion, and migration of macrophages. At the last, the relationship between SIRP $\alpha$ and $\mathrm{NF}-\kappa \mathrm{B}$ was studied at regulating the phenotype of macrophages.

\section{RESULTS}

\section{The expression of SIRP $\alpha$ in OLK and OSCC specimens}

SIRPa was expressed in the cytoplasm and frequently observed in OLK and OSCC samples (Figure 1A). Few cells were positively stained in NOM. The expression of SIRP $\alpha$ in LR-OLK, HR-OLK, and OSCC were increased comparing with NOM $(p<0.05)$. The expression of SIRP $\alpha$ in LR-OLK was higher than OSCC ( $p=0.04)$ (Figure 1D). Compared with OSCC, the expression of SIRP $\alpha$ in HR-OLK was lower than OSCC, but there was no significant difference $(p=0.15)$.

\section{Correlation between macrophages and SIRP $\alpha$ in OLK and OSCC}

To investigate the expression of SIRP $\alpha$ on macrophages in OLK and OSCC, the expression of two macrophage markers, CD68 (macrophages) and CD163 (M2 macrophages) were used to identify the precise location of SIRP $\alpha$. The majority of the infiltrated macrophages were located in the subepithelial stroma. CD163-positive and CD68-positive macrophages were rarely detected in the epithelial stroma of the NOM specimens. Although the expression of CD163-positive macrophages was slightly lower than that of CD68-positive macrophages, the difference was not significant $(p>0.05)$. Both the expression of CD68 and CD163 were detected increased significantly by pathological grade (Figure 1B, 1C). The expression of CD68 and CD163 in LR-OLK $(p<0.05)$, HR-OLK $(p<0.05)$, and OSCC $(p=0.0005)$ were gradually increased as compared with that in NOM. In addition, the expression of CD68 on macrophages positively correlated with the expression of $\operatorname{SIRP} \alpha$, and the expression of CD163 on macrophages negatively correlated with the expression of $\operatorname{SIRP} \alpha(p<0.0001, p=0.0001$; Figure 1E, 1F).

To further characterize the expression of SIRP $\alpha$ on macrophages, we used double-labeling immunofluorescence to detect the coexpression of CD68, CD163, and SIRP $\alpha$. The expression of SIRP $\alpha$ was mainly located in the subepithelial lesion in OLK, and in OSCC was infiltrated in epithelial lesion. CD163 was expressed in the subepithelial lesion, and CD163 cells mainly located under the basal lamina co-localized with $\operatorname{SIRP} \alpha$ (Figure 2A, 2B). The percentages of CD163-positive macrophages and SIRP $\alpha$-positive cells were increased in OLK than NOM $(p<0.01)$. The percentages of CD68positve macrophages in OLK co-expressed with SIRP $\alpha$ were significant higher than NOM ( $p<0.05$; Figure $2 \mathrm{C})$. The percentages of CD163-positive macrophages or CD68-positive macrophages co-expressed with SIRP $\alpha$ were increased in OLK than OSCC $(p<0.05)$.

\section{Conditioned media of OSCC cell lines reduced the expression of SIRP $\alpha$ on macrophages}

The co-expression of CD68 and SIRP $\alpha$ was examined using double-labeling immunofluorescence to detect the sub-cellular expression of $\operatorname{SIRP} \alpha$ on macrophages. PMA stimulated THP-1 cells into macrophages. Macrophages cultured with the conditioned media of Cal-27 cells after stimulation. CD68 and SIRP $\alpha$ expression were found on the cytoplasm of macrophages (Figure 3A).

Flow cytometric analysis was applied to study the effect of cancer cells on the expression of SIRP $\alpha$ on macrophages. THP-1 cells were cultured with conditioned media of Cal-27 or SCC-9 cell lines for $0,1,3,5,7$, and 9 days after stimulated by PMA. The expression of SIRP $\alpha$ was decreased gradually, manifesting time-dependent pattern (Figure 3B, 3C). 
A
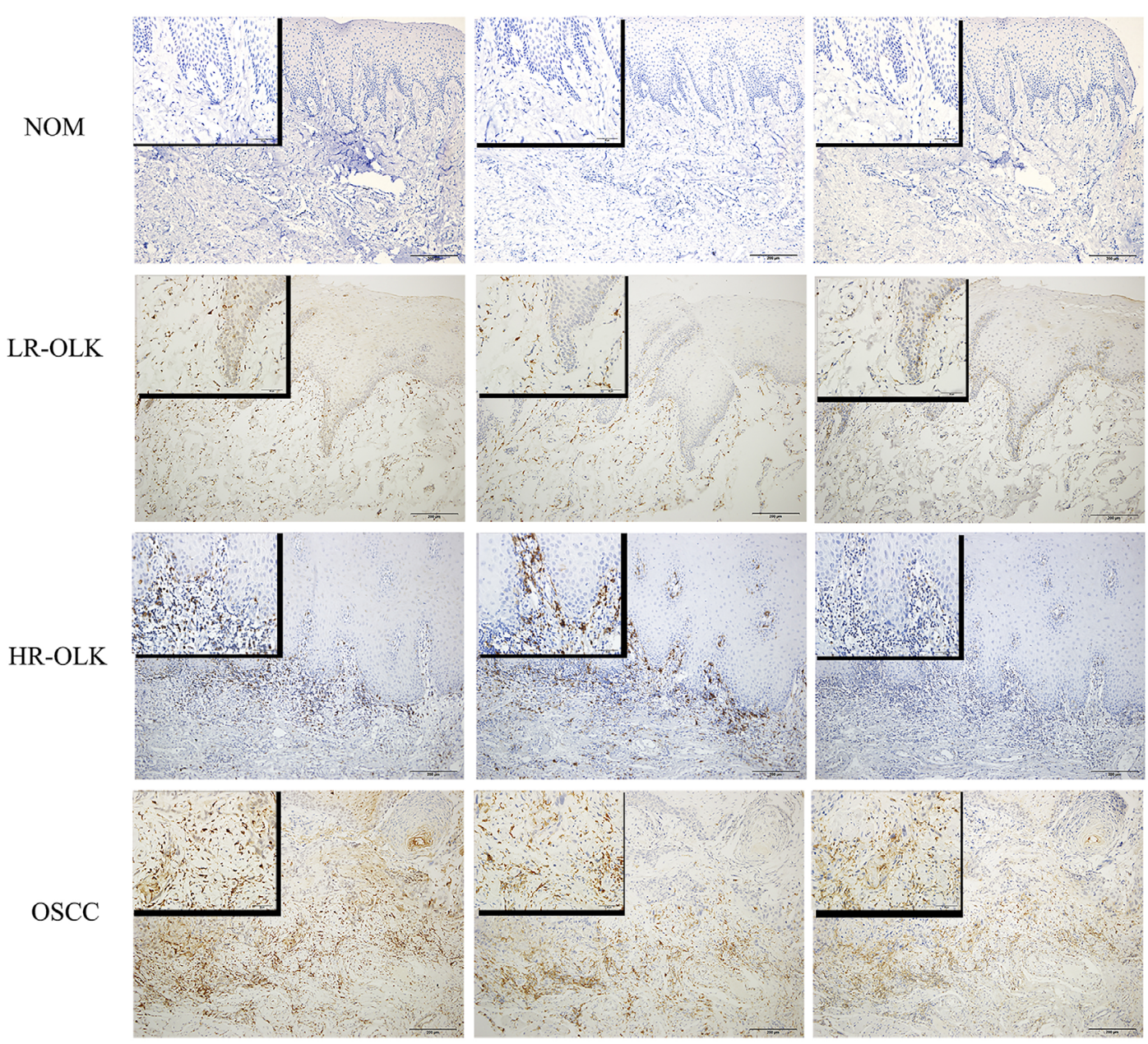

B
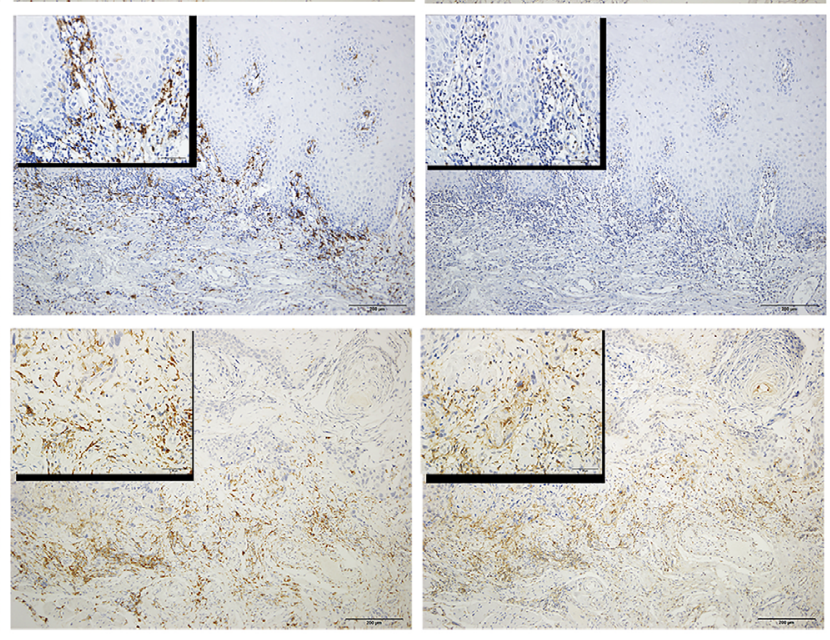

C

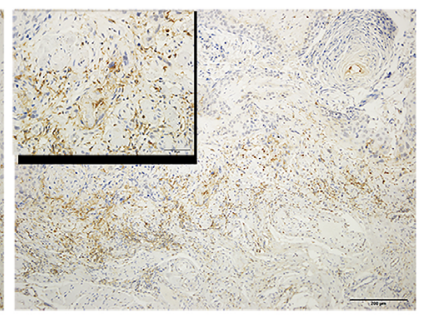

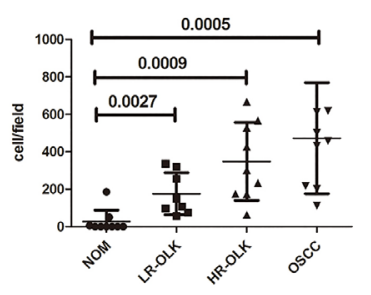

CD68

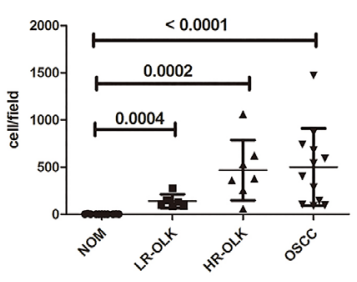

CD163
D

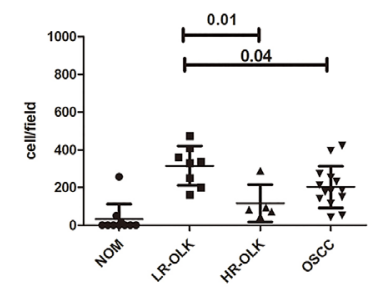

SIRP $\alpha$
E

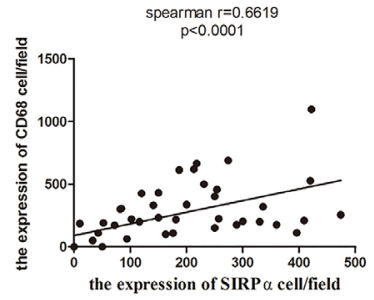

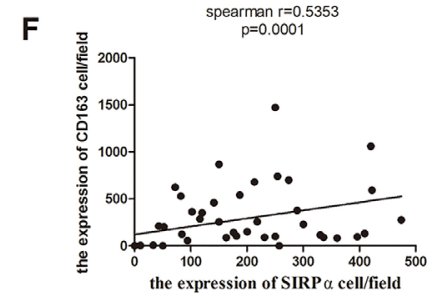

Figure 1: The expression of CD68, CD163, and SIRPa in NOM, LR-OLK, HR-OLK, and OSCC specimens $(\times 100)$ ( $\times 400)$. A. The number of expression of CD68 B. and CD163 C. were increased from NOM to OSCC, along with the rising of histological grades of dysplasia. The expression of SIRP $\alpha$ was higher in LR-OLK than HR-OLK and OSCC D. Spearman's rank analysis was used to analysis the correlation between CD68, CD163, and SIRP $\alpha \mathbf{E}, \mathbf{F}$. Data are presented as mean \pm SD, One way ANOVA with post Tukey test. 
DAPI

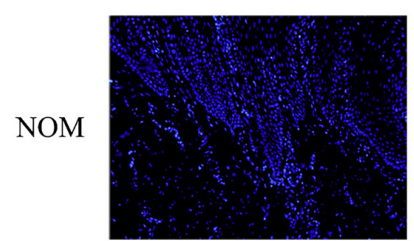

OLK
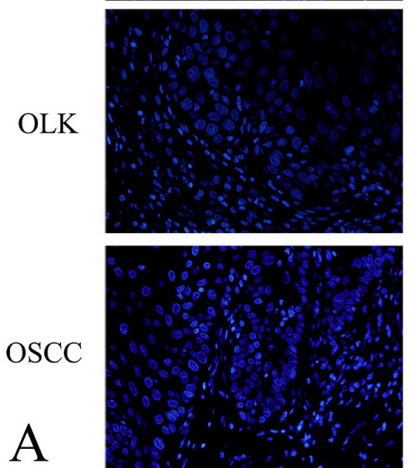

DAPI
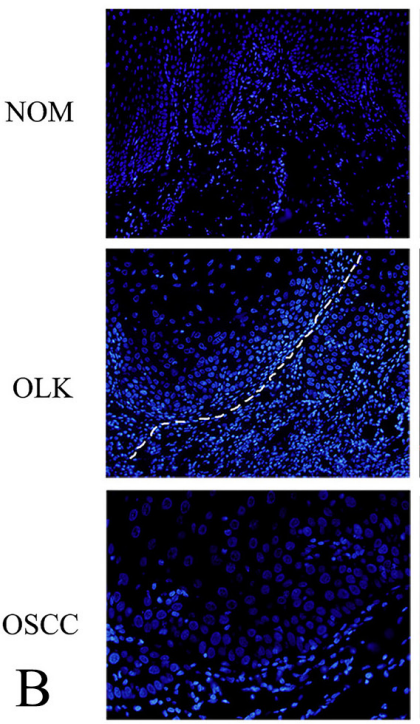

C

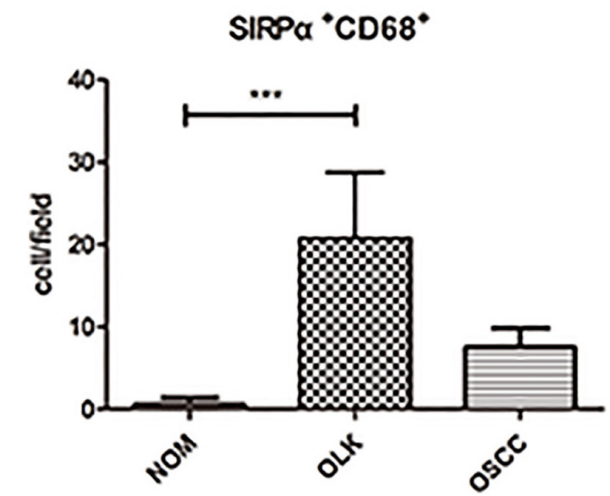

CD163
SIRPa
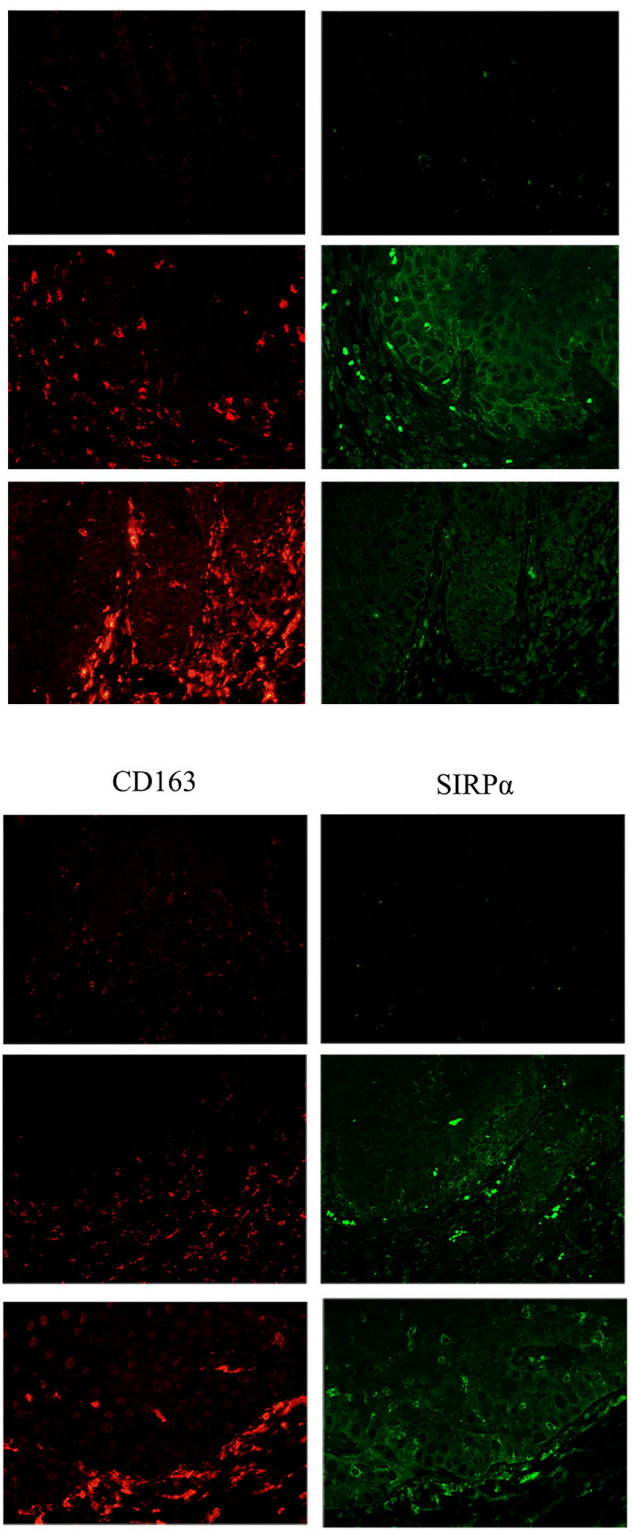

$\operatorname{SIRP} \alpha$
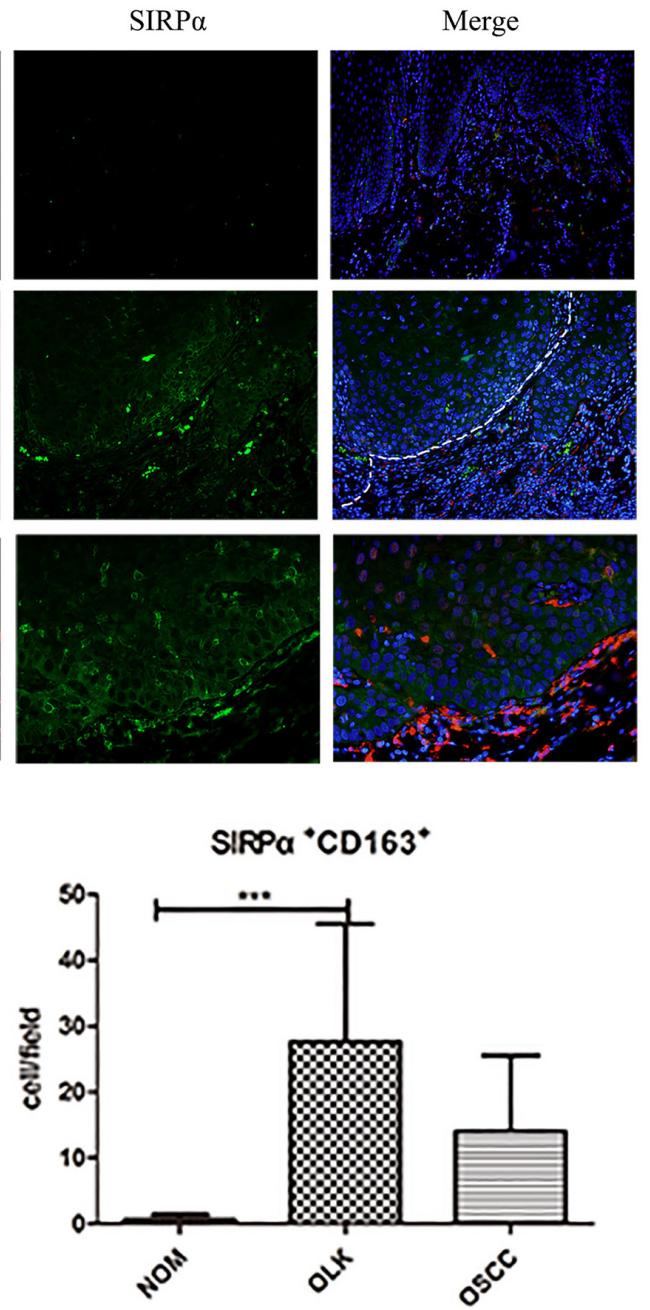

Figure 2: The expression of SIRPa, CD68, and CD163 in OLK and OSCC sample. A. Double-labeling immunofluorescence for CD68 and SIRP $\alpha$ in OLK and OSCC samples. B. Double-labeling immunofluorescence for CD163 and SIRP $\alpha$ in OLK and OSCC samples. C. The infiltrated cells of SIRP $\alpha^{+} \mathrm{CD} 68^{+}$and $\mathrm{SIRP} \alpha^{+} \mathrm{CD} 163^{+}$in OLK were higher than NOM and OSCC. Data are presented as mean $\pm \mathrm{SD}$, One way ANOVA with Tukey test. * $p<0.05$, * $* p<0.01$, and $* * * p<0.001$. 


\section{Cal-27 cell lines promoted the production of M2- polarized macrophages cells}

To determine the effect of oral cancer cell lines on PMA-treated THP-1 cells, we induced the TPH-1 cells into macrophages with PMA for the first $24 \mathrm{~h}$ and cocultured them with Cal-27 cell lines in transwell plate for another $24 \mathrm{~h}, 48 \mathrm{~h}$. The treated THP-1 cells underwent morphological changes characterized by increased size and improved adherence, implying their differentiation from monocytes into macrophages. As shown in Figure $4 \mathrm{~A}$, the cells treated with PMA only had high TNF- $\alpha$, and IL-6 levels and low TGF- $\beta$ level. By contrast, comparing with PMA group, Cal-27 group elevated the expression of CD163, IL-10, and TGF- $\beta$ mRNA. The expression of IL-10 was increased dramatically in $24 \mathrm{~h}$ and increased slightly after $48 \mathrm{~h}$ co-culture $(p<0.05)$. Furthermore, the expression of IL-6, and TNF- $\alpha$ mRNA were decreased. These results indicated that in the co-cultured system, macrophages were induced to M2 phenotype.

Cells were also treated with IL-4/LPS to set as the positive controls. After THP-1 cells were induced by PMA and stimulated with LPS, the expression of CD68 protein in macrophages was up-regulated and the expression of CD163 protein was decreased comparing with Cal-27 group (Figure 4A). The cells in IL-4 group were similar to M2-polarized macrophages in terms of low TNF- $\alpha$, and
IL-6 levels and high CD68, CD163, and TGF- $\beta$ levels. Also, under hypoxic environment, comparing with $\mathrm{Cal}-27$ group, the expression of CD68, IL-10, and TGF- $\beta$ mRNA were increased in hypoxia group and the expression of CD163 mRNA was decreased (Figure 4A).

\section{SIRP $\alpha$ was associated with the phenotype of macrophages switch}

In the co-cultured system, the expression of SIRP $\alpha$ mRNA and protein on macrophages was slightly increased in Cal-27 group than PMA group in $24 \mathrm{~h}$. After $48 \mathrm{~h}$ cocultured with Cal-27 cells, the expression of SIRP $\alpha$ mRNA was decreased dramatically (Figure 4C, Figure 4A). To address whether SIRP $\alpha$ regulates the phenotype switch of macrophage, SIRP $\alpha$ expression in THP-1 was inhibited by siRNA transfection (si-KD). Compared with the Cal-27 group, the expression of SIRP $\alpha$ in si-KD group was decreased after co-cultured (Figure 4C). We further compared the mRNA expression of M1-related and M2-related genes of macrophages in Cal-27 control group and si-KD group. In si-KD group, the expression of IL-10, TGF- $\beta$ were elevated, and the production of IL6 , TNF- $\alpha$ were down-regulated (Figure 4B). Moreover, the expression of CD68, CD163 mRNA were increased significantly in si-KD group.
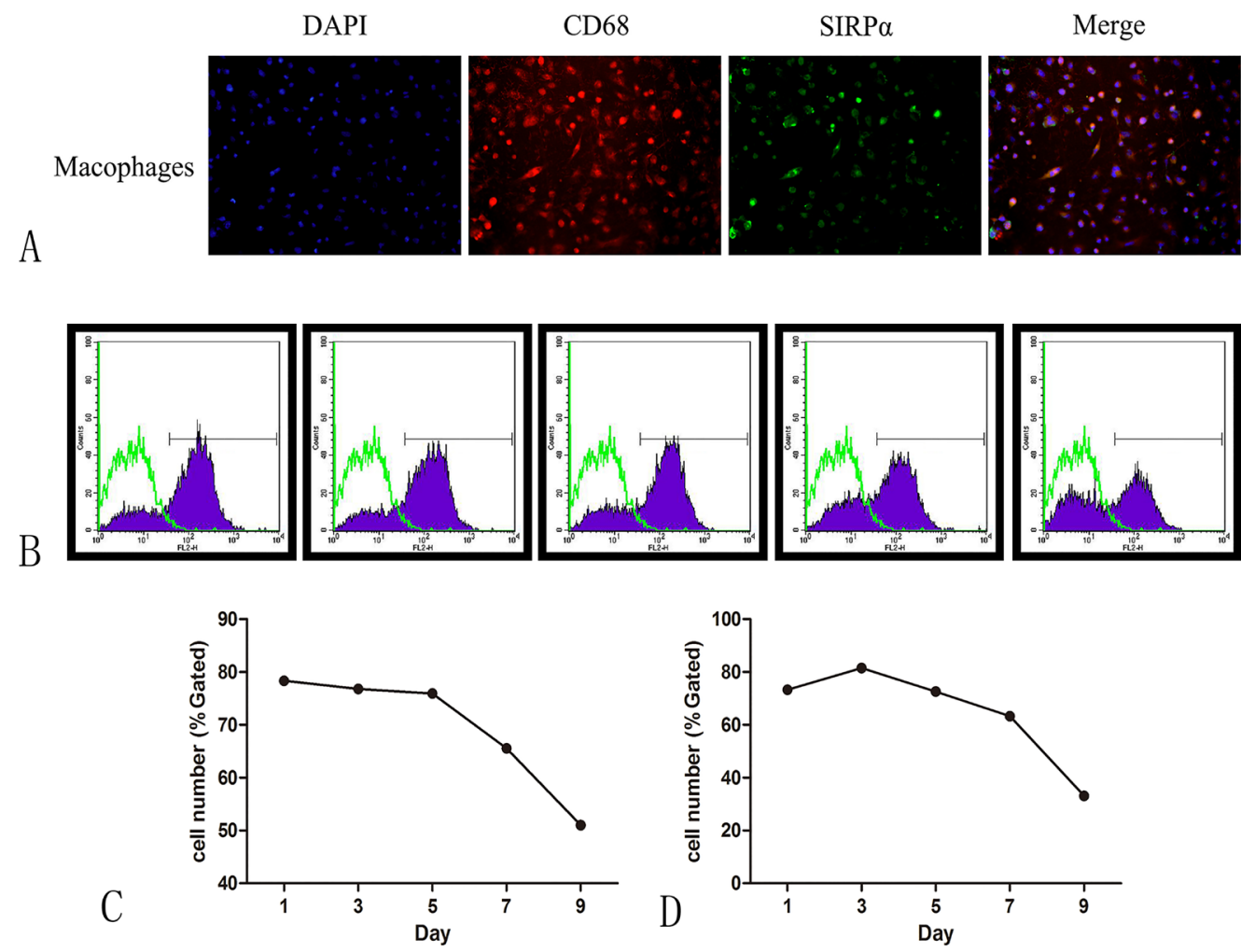

Figure 3: The expression of SIRP $\alpha$ on macrophages after co-culture with the supernatant of oral cancer. A. CD68 were co-expressed with SIRP $\alpha$ on macrophages after co-cultured with Cal-27 or SCC-9. B. The expression of SIRP $\alpha$ was decreased gradually when macrophages were co-cultured with supernatant of SCC-9 C. or Cal-27 D. cells for 1, 3, 5, 7, and 9 days. 
Furthermore, under hypoxic environment, both protein and mRNA expressions of SIRP $\alpha$ on macrophages in hypoxia group were up-regulated than Cal-27 group, while slightly decreased than LPS group $(p<0.05)$ (Figure $4 \mathrm{C}$, Figure 4A). In LPS group, the expression of SIRP $\alpha$ protein was increased than Cal-27 group $(p<0.05)$. Stimulated by IL-4, macrophages expressed less SIRP $\alpha$ than macrophages in LPS and PMA groups $(p<0.05)$ (Figure 4A). These results demonstrated that these components existing in oral cancer microenvironment may influence SIRP $\alpha$ expression on macrophages.

\section{SIRP $\alpha$ negatively regulated the proliferation of macrophages}

To investigate the effect of $\operatorname{SIRP} \alpha$ on the proliferation of macrophages, CCK8 assay was utilized. The proliferation of macrophages in si-KD group were upregulated than PMA control group ( $p<0.01$; Figure 5A).

\section{SIRP $\alpha$ negatively regulated macrophages recruitment and invasion to OSCC cells}

Transwell assay was used to investigate whether SIRP $\alpha$ could regulate macrophages migration and invasion during tumor exposure. In si-KD group, after $24 \mathrm{~h}$ and 48 $\mathrm{h}$ of co-incubation with tumor cells, the invasive capacity of macrophages was slightly decreased than Cal-27 and significantly increased than PMA group $(p>0.05, p<0.05)$ (Figure 5E, 5F). The migration ability was significantly increased comparing with PMA group and decreased than Cal-27 group when SIRP $\alpha$ expression on macrophages was silenced $(p<0.05)$ (Figure 5C, 5D).

\section{Knockdown of SIRP $\alpha$ inhibited phagocytosis ability of macrophages}

To evaluate whether $\operatorname{SIRP} \alpha$ could influence the phagocytosis ability of macrophages, neutral red uptake assay was utilized. Comparing with PMA control group and LPS group, the phagocytosis ability of macrophages in si-KD group was inhibited significantly $(p<0.01)$. The same influence was found in Cal-27 group $(p<0.01)$ (Figure 5B).

\section{SIRPa on macrophages inhibited the recruitment of Cal-27 cells}

Since SIRP $\alpha$ significantly inhibited the macrophages recruitment and invasion to Cal-27 cells, we then investigated the influence of SIRP $\alpha$ on Cal-27 cells. After
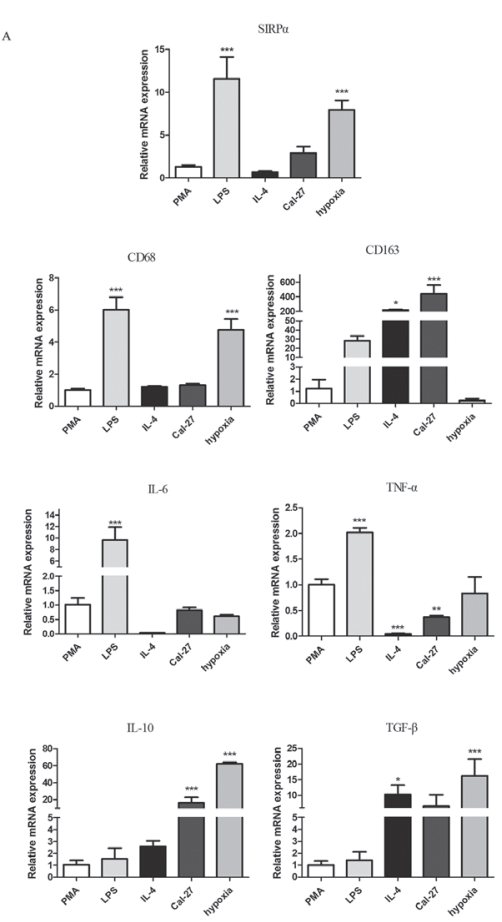
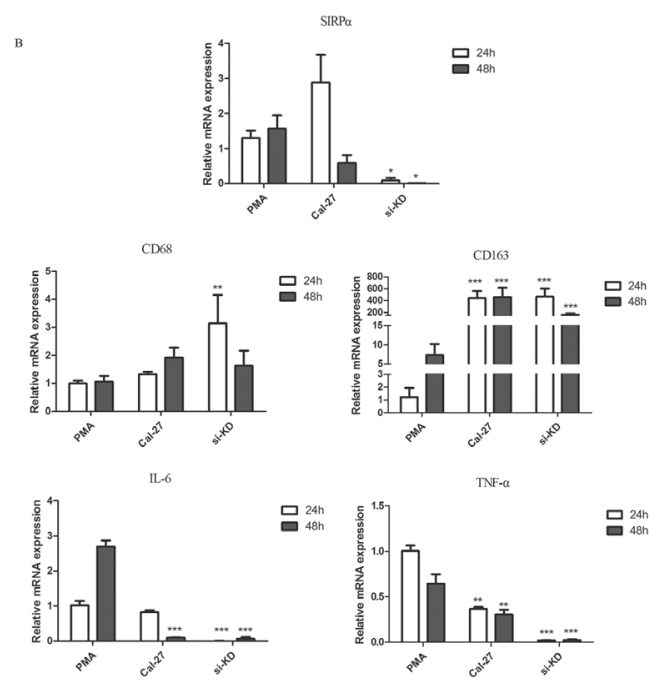

믐 ${ }^{24 h}$
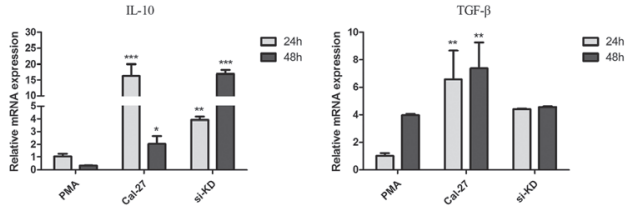

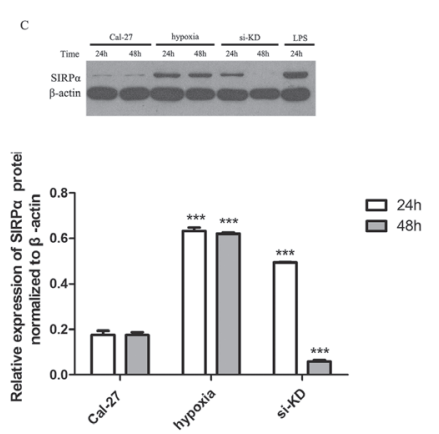

Figure 4: Cytokine profiles and the expression of SIRPa, CD68, and CD163 on macrophages. THP-1 cells were stimulated by different factors after induced by PMA into macrophages. A. Macrophages stimulated by LPS (1 $\mu \mathrm{g} / \mathrm{mL})$ for $24 \mathrm{~h}$ expressed high SIRP $\alpha$, CD68, IL-6, and TNF- $\alpha$, and displayed low IL-10 and TGF- $\beta$. In IL-4 group, macrophages decreased the expression of SIRP $\alpha$, CD68, IL-6, TNF- $\alpha$ while increased the expression of CD68, CD163, and TGF- $\beta$ after treated with $10 \mu \mathrm{g} / \mathrm{mL}$ for 24 h. Macrophages under hypoxia for $24 \mathrm{~h}$ increased the production of SIRP $\alpha$, CD68, IL-10, and TGF- $\beta$, while decreased the production of IL- 6 and TNF- $\alpha$. B. Macrophages were co-cultured with Cal-27 cells after knockdown of SIRP $\alpha$. In si-KD group, macrophages displayed low SIRP $\alpha$, IL-6, TNF- $\alpha$, and high CD68, CD163, IL-10, and TGF- $\beta$. C. The protein expression of SIRP $\alpha$ in si-KD group was increased than Cal-27 group in $24 \mathrm{~h}$ but decreased significant in $48 \mathrm{~h}$ co-culture. Analysis via one-way ANOVA with Tukey test. $* p<0.05,{ }^{*} p<0.01$, and $* * * p<0.001$ versus PMA group. 
A

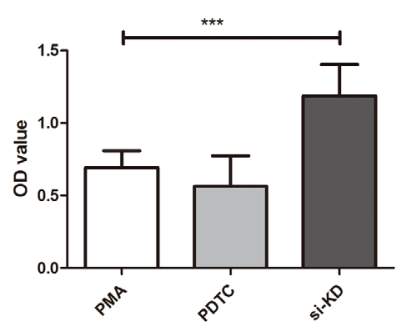

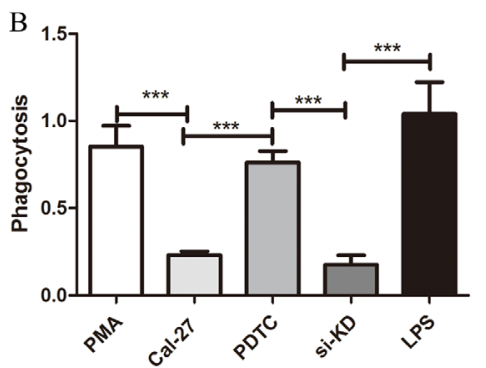

PDTC

i-KD

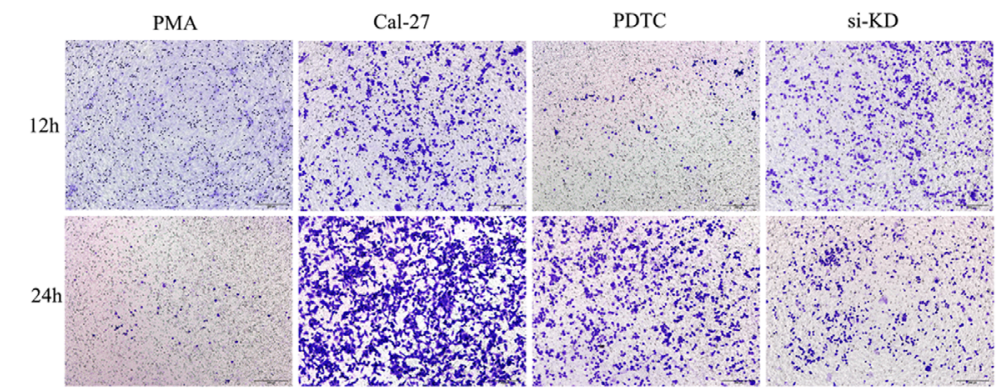

D
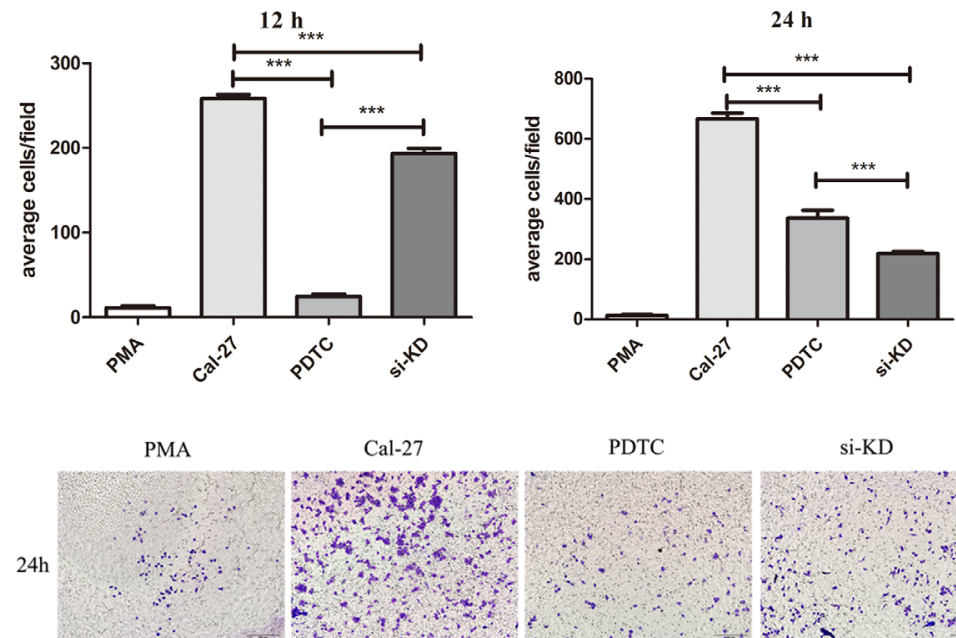

Cal-27

PDTC

si-KD

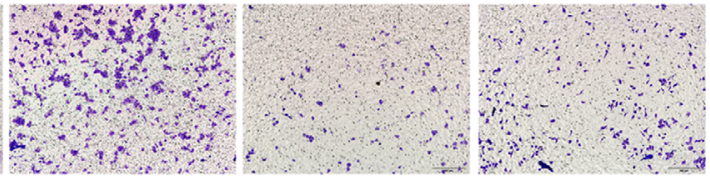

$48 \mathrm{~h}$

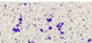

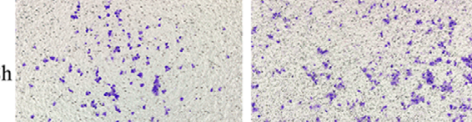

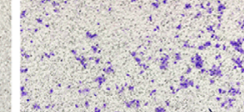

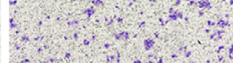

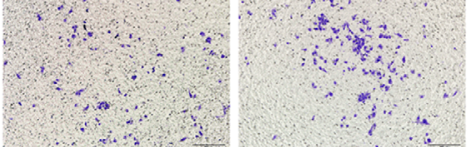

E
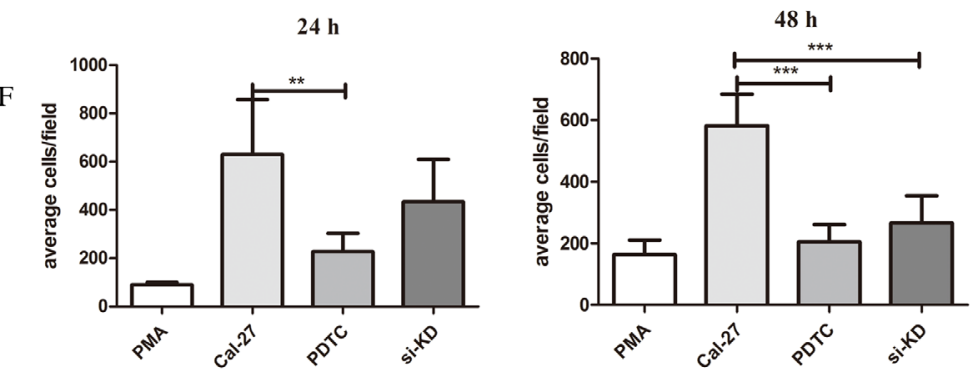

Figure 5: SIRP $\alpha$ and NF- $\mathrm{B} B$ regulated the proliferation, phagocytosis, migration, and invasion of macrophages. THP1 cells were stimulated by LPS, siRNA, and PDTC after induced by PMA into macrophages. After stimulation, macrophages were coculture with Cal-27 cells in Cal-27, si-KD, and PDTC (inhibitor of NF-kB) groups. A. the proliferation of macrophages was increased after knockdown of SIRP $\alpha$. B. the phagocytosis ability of macrophage was inhibited in si-KD group while no significant change in PDTC group. $\mathbf{C}$ and $\mathbf{D}$. the migration cells were decreased both in si-KD group and PDTC group. $\mathbf{E}$ and $\mathbf{F}$. the invasion cells were decreased both in si-KD group and PDTC group. Analysis via one-way ANOVA with Tukey test. ${ }^{*} p<0.05,{ }^{* *} p<0.01$, and ${ }^{* * *} p<0.001$. 


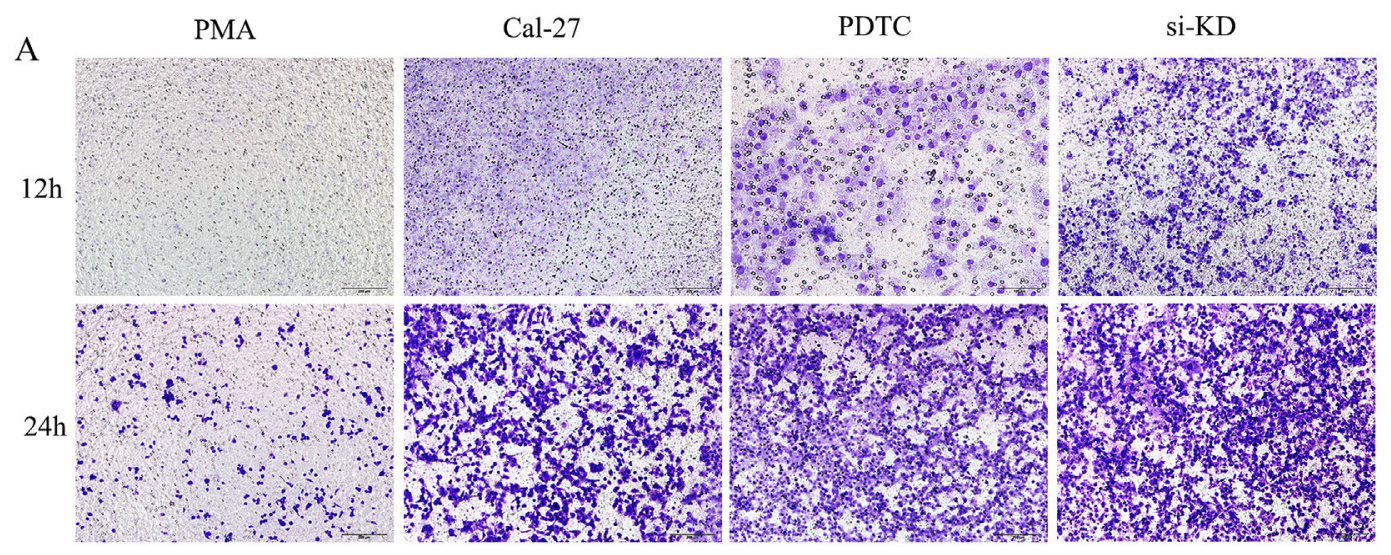

B
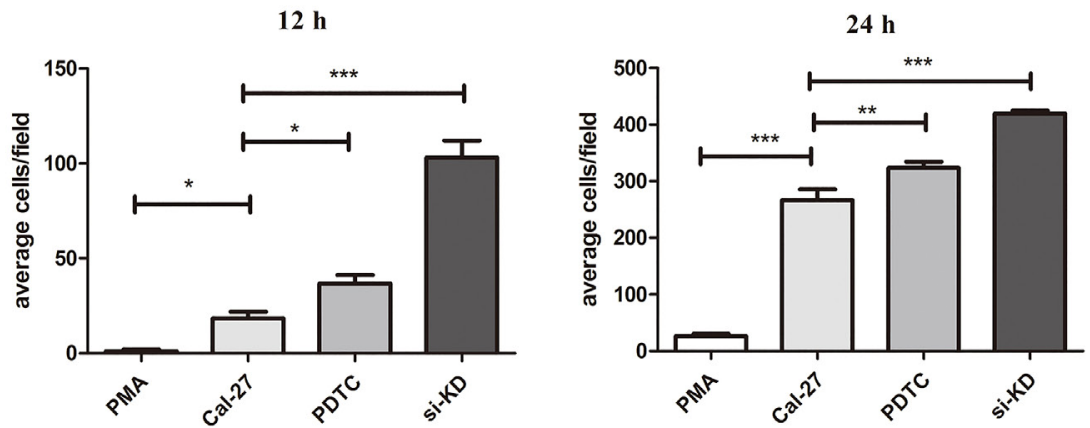

$\mathrm{C}$

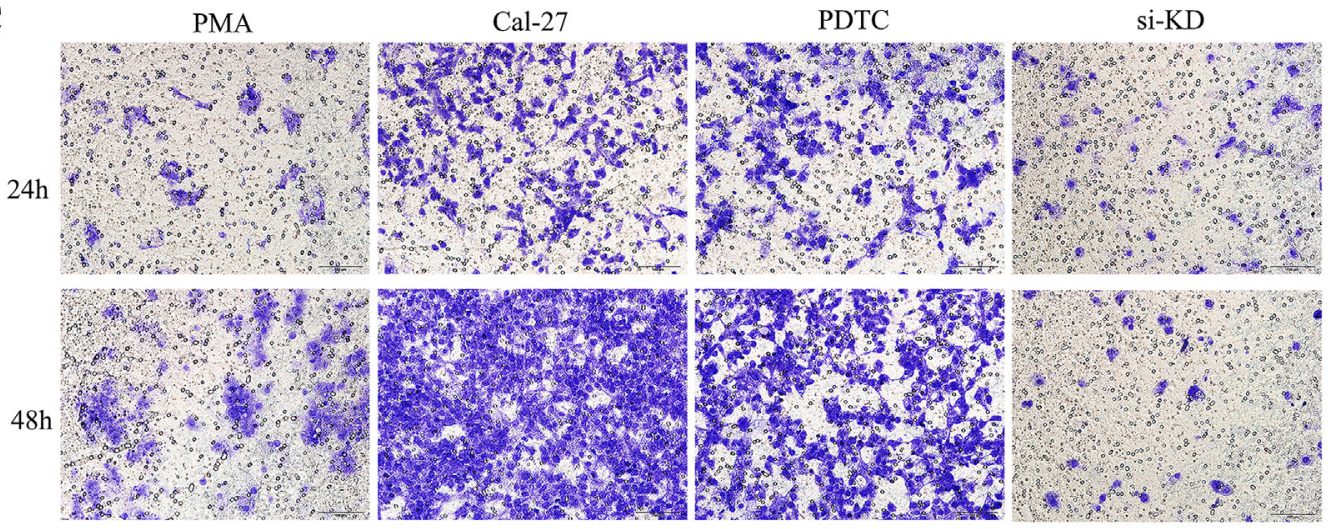

$\mathrm{D}$
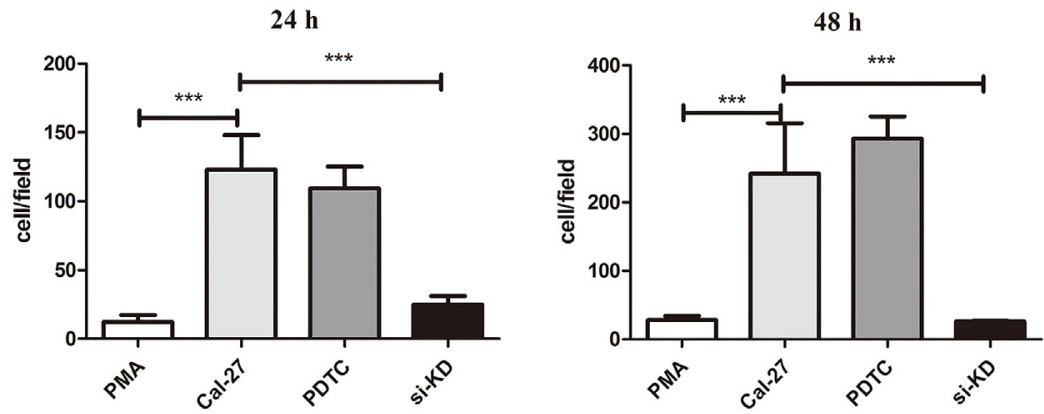

Figure 6: SIRP $\alpha$ and NF-KB regulated the migration and invasion of Cal-27 cells. THP-1 cells were stimulated by siRNA and PDTC (inhibitor of NF-KB) after induced by PMA into macrophages. After stimulation, macrophages were co-culture with Cal-27 cells in Cal-27, si-KD, and PDTC groups. A and B. the migration Cal-27 cells were increased in si-KD group and PDTC group. $\mathbf{C}$ and $\mathbf{D}$. the invasion Cal-27 cells were decreased in si-KD group and PDTC group. Analysis via one-way ANOVA with Tukey test. ${ }^{*} p<0.05,{ }^{* *} p<$ 0.01 , and $* * * p<0.001$. 
knockdown of SIRP $\alpha$ in macrophages, the migration of Cal-27 cells were increased in si-KD group than Cal-27 group $(p<0.05)$ (Figure 6A, 6B). At the meantime, the invasion of Cal-27 cells was decreased in si-KD group than Cal-27 and PMA groups $(p<0.05)$ (Figure 6C, 6D).

\section{SIRP $\alpha$ was regulated by $\mathrm{NF}-\kappa \mathrm{B}$ signaling pathway}

$\mathrm{NF}-\kappa \mathrm{B}$ is considered as important transcription factor in macrophages linking inflammation and cancer, the study explored whether NF- $\kappa \mathrm{B}$ could affect the expression of SIRP $\alpha$ and the polarization of macrophages [24]. The expression of $\operatorname{SIRP} \alpha$ was analyzed with western blot to determine the role of NF- $\mathrm{KB}$ during polarization of THP1 cells. Comparing with Cal-27 group, the expression of
SIRP $\alpha$ protein was inhibited in si-KD group (Figure 4C). From another direction, after using PDTC (pyrrolidine dithiocarbamate ammonium) to inhibit the activation of $\mathrm{NF}-\kappa \mathrm{B}$, the expression of $\operatorname{SIRP} \alpha$ protein was up-regulated than Cal-27 group (Figure 7B). Moreover, in PDTC group the macrophages were switch into M1 phenotype with the elevated IL- 6 and TNF- $\alpha$ mRNA levels, and reduced CD163, IL-10 and TGF- $\beta$ mRNA levels (Figure 7A).

\section{NF-кB regulated macrophages phagocytosis, recruitment and invasion abilities}

To determine whether the inhibitor of NF- $\mathrm{NB}$ has an effect on the proliferation, phagocytosis ability, migration and invasion of macrophages, CCK-8, co-culture assay and transwell assay were performed. Compared with
A
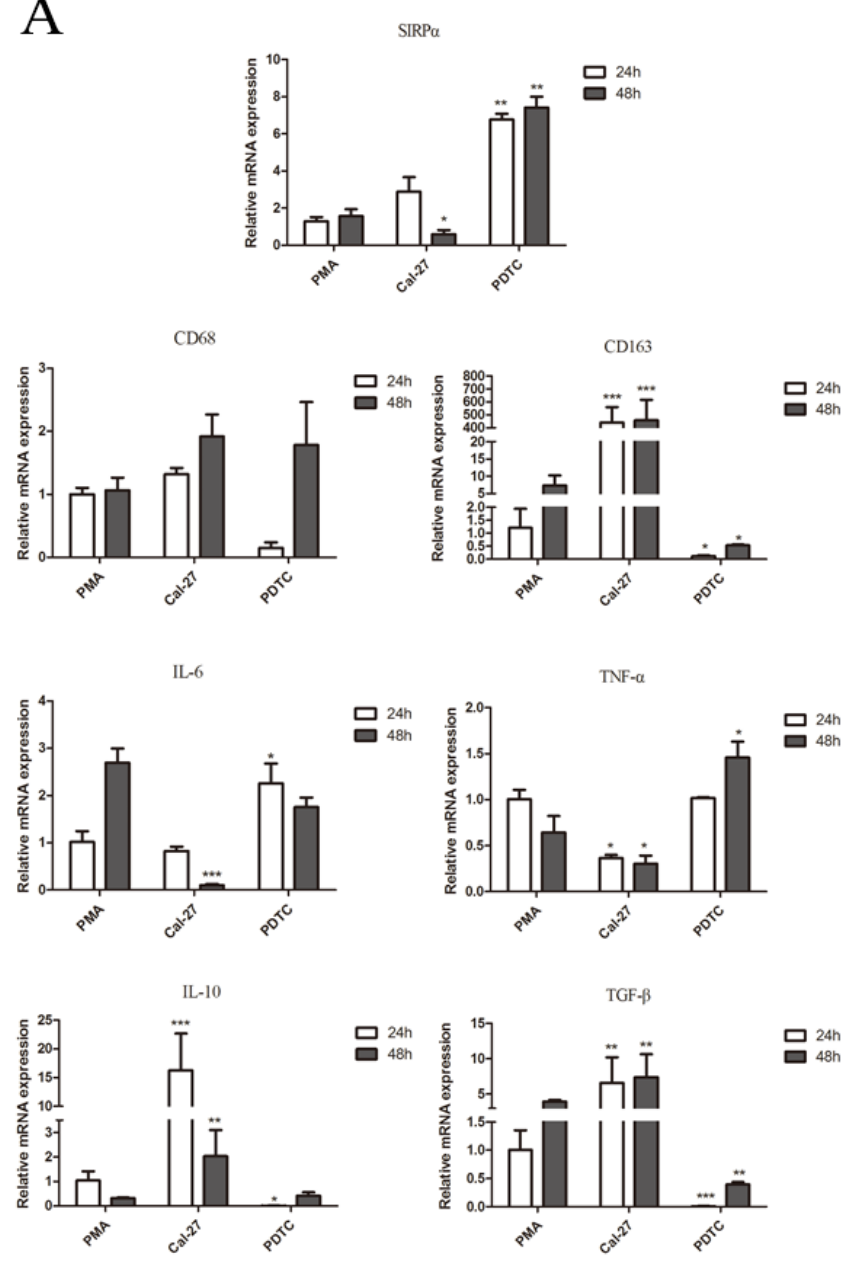

B
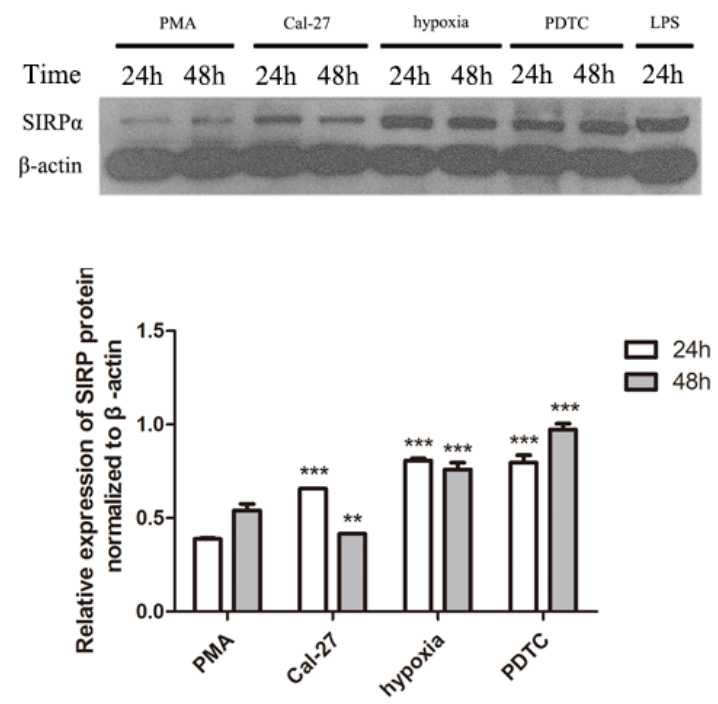

Figure 7: The effect of NF-кB on the expression of cytokine profiles, CD68, CD163, and SIRP $\alpha$ on macrophages. THP-1 cells were stimulated by LPS, hypoxia, and PDTC (inhibitor of NF- $\mathrm{kB}$ ) after induced by PMA into macrophages. After stimulation, macrophages were co-culture with Cal-27 cells for $24 \mathrm{~h}$ and $48 \mathrm{~h}$ in Cal-27, hypoxia, and PDTC groups. A. Macrophages co-cultured with Cal-27 cells for $24 \mathrm{~h}$ and $48 \mathrm{~h}$ after PDTC $(50 \mu \mathrm{mol} / \mathrm{mL})$ inhibited NF- $\kappa$ B in macrophages. Macrophages in PDTC group presented high SIRP $\alpha$, IL-6, TNF- $\alpha$, and low CD68, CD163, IL-10, and TGF- $\beta$. B. The expression of SIRP $\alpha$ in Cal-27 group was increased than PMA group. In PDTC group, the expression of SIRP $\alpha$ was increased than Cal-27 group after inhibiting NF- $\kappa$ B. The expression of SIRP $\alpha$ in LPS and hypoxia groups were increased. Analysis via one-way ANOVA with Tukey test. $* p<0.05, * * p<0.01$, and $* * * p<0.001$ versus PMA group. 
PMA group, macrophages in PDTC group were present no significant inhibition in proliferation (Figure 5A). The phagocytosis ability of macrophage was enhanced in PDTC group than Cal-27 group $(p<0.01)$ (Figure 5B). After stimulated by PDTC, the migratory ability of macrophages were significantly inhibited than in Cal-27 group (Figure $5 \mathrm{C}, 5 \mathrm{D})$. The transwell invasion assay also showed that the number of invasive cells stimulated by PDTC were significantly lower compared with the Cal-27 group both in $24 \mathrm{~h}$ and $48 \mathrm{~h}(p=0.0081, p=0.004)$ (Figure 5E, 5F).

\section{$\mathrm{NF}-\kappa \mathrm{B}$ regulated recruitment and invasion abilities of Cal-27 cells}

The influence of NF- $\kappa \mathrm{B}$ in macrophages on the recruitment and invasion abilities of Cal-27 cells was further explored. Cal-27 cells co-cultured with macrophages in PDTC group and the migration cells were increased than PMA group in $12 \mathrm{~h}$ and $24 \mathrm{~h}(p<0.05$, $p<0.01$ ) (Figure 6A, 6B). In invasion experiment that invaded Cal-27 cells in PDTC group were increased $(p<0.05)$ (Figure 6C, 6D).

\section{DISCUSSION}

In the tumor microenvironment, macrophages comprise a major population of tumor-infiltrating immune cells [25]. Macrophages exhibit either pro- or anti-tumor properties depending on their phenotype [25]. In this study, we detected the expression of SIRP $\alpha$ in OLK and OSCC, and the correlation with macrophages. In exploring the effect of SIRP $\alpha$ on macrophages in OSCC, we found that $\operatorname{SIRP} \alpha$ was down-regulated on macrophages when co-cultured with OSCC, and increased the phagocytosis ability of macrophages. Furthermore, it negatively regulated migration and invasion of macrophages to OSCC. At the meantime, our data demonstrated that $\operatorname{SIRP} \alpha$ was associated with the phenotype switch of macrophages through NF- $\kappa \mathrm{B}$ pathway and played a negative role in tumor migration.

TAMs is a predominant cellular component in tumor microenvironment, promoting the progression, angiogenesis, and metastasis in various tumors [26, 27]. The present study found that in OLK and OSCC, the expressions of CD163 ${ }^{+}$ macrophages was higher than that in normal oral mucosa, demonstrating the important role of M2 macrophages in the development of OLK and OSCC [28]. Besides, Mori et al. proved that the expressions of $\mathrm{CD}_{163^{+}}$cells were significantly increased along with the pathological grade in OSCC and concluded that the infiltrated TAMs have an M2 phenotype in OSCC [29]. In addition, there was a study announcing that the $\mathrm{CD} 163^{+}$macrophages in OLK appear to possess an M1 phenotype [30]. Pan et al. found that in the tumor tissues, macrophages present an immunosuppressive phenotype like M2. However, a larger amount of M1-like cells are contained in the peritumor tissues [24]. It might suppose that macrophages were educated by tumor cells from M1 to M2 phenotype, and this process was along with the progression of OLK and OSCC. SIRP $\alpha$ are members of glycoprotein expressed on macrophages, promoting immune recognition and priming phagocytosis of pathogens or malignant cell [31]. The present study found the expression of SIRP $\alpha$ in LR-OLK was higher than OSCC. Moreover, the expression of SIRP $\alpha$ was associated with macrophages. In accordance with this, gradually decreased expression of $\operatorname{SIRP} \alpha$ on macrophages was appeared in vitro co-culture assay. These results might suggesting that $\operatorname{SIRP} \alpha$ could plays a vital role in the progression of OLK and OSCC, meanwhile, SIRP $\alpha$ could be co-marker with macrophages to prognosis the OLK and OSCC.

$\mathrm{SIRP} \alpha-C D 47$ interaction is served as a "don't eat me" and "self-recognized" signaling and it could be a therapeutic target for human tumors [23, 32-34]. When tumor cells treated with anti-CD47 antibodies, macrophages enhanced the phagocytic capability against tumor cells [35]. Considering the relatively limited tissue expression, SIRP $\alpha$ may be a better target compared with agents targeting CD47 which is ubiquitously expressed [23]. In this study, we observed that macrophages cocultured with OSCC cells expressed lower level of SIRP $\alpha$ compared with control group. Meanwhile, in SIRP $\alpha$ knockdown macrophages, the phagocytosis ability of macrophages were inhibited. Thus, it demonstrated that OSCC might inhibit the phagocytosis ability of macrophages through down-regulated the expression of SIRP $\alpha$. Many studies have shown that the invasive and migratory behavior of malignant cells could be increased by macrophages [36]. The current data represented that relative lower expression of SIRP $\alpha$ on macrophages in co-culture assay was correlated with the recruitment and invasion of oral cancer cells, indicating that oral cancer might exploit the macrophages with $\mathrm{SIRP} \alpha$ reduction to profit themselves. Interestingly, even without cell-cell direct interaction, knockdown of SIRP $\alpha$ on macrophages could increase the migration of Cal-27 cells, suggesting that the substance released by macrophages may play a critical part in tumor migration.

Macrophages can be differentiated into M1- or M2-like macrophages, and then different phenotype cells produce Th1 or Th2 cytokines [7]. M1 macrophages produce several pro-inflammatory cytokines, such as TNF- $\alpha$ and IL-6, and the M2-like phenotype of TAM increase the expression of immunosuppressive cytokines such as TGF- $\beta$ and IL-10. [5]. Importantly, IL-10 is an immunosuppressive cytokine and lead to M2 macrophage differentiation [37]. Our data indicated that macrophages produced high level of IL-10 involving in the macrophages differentiation in the first $24 \mathrm{~h}$ co-culture and kept the production of IL-10 in a stable level. In addition to activating macrophages, in the tumor environment, $\mathrm{TNF}-\alpha$ is able to promote angiogenesis [38]. A significant increase was observed in the production of Th1 cytokines by the differentiated M1 
macrophages stimulated by LPS. Meanwhile, stimulated by IL-4, macrophages increased the secretion of Th2 cytokines. Our study further showed that pro-inflammatory cytokines genes were inhibited when knockdown the expression of $\operatorname{SIRP} \alpha$, along with the adjustment of macrophages immune status, suggesting that SIRP $\alpha$ might play a possible role in regulating macrophages phenotype switch. However, it was hard to elaborate why the protein of $\operatorname{SIRP} \alpha$ was increased when macrophages co-cultured with Cal-27. We speculated that macrophages would switch to M1 phenotype before being re-educated to M2 macrophages by cancers. Mori et al. indicated that a Th1-dominated microenvironment was formed in OLK lesions and suggested that Th1-derived IFN- $\gamma$ could be able to polarize the infiltrated macrophages switch to the M1 phenotype [30]. However, in premalignant lesions, alteration in the phenotypes and features of TAMs during tumor development have not been characterized. Thus, further investigation is needed to explore the precise role of $\operatorname{SIRP} \alpha$ on macrophages under premalignant microenvironment.

Various studies have demonstrated that inhibition of NF-B activation helps to drive the tumor-promoting phenotype of TAMs to antitumor phenotype [13, 39]. Redirecting M2-like TAM toward M1-like phenotype by reactivating $\mathrm{NF}-\kappa \mathrm{B}$ induced significant antitumor immune response in mammary carcinoma [40]. Besides, TAM increased their tumoricidal activity after targeted deletion or inhibition of IKK $\beta$ [40]. In spite of the fact that $\mathrm{NF}-\kappa \mathrm{B}$ is viewed as a noteworthy pro-inflammatory transcription factor, recent studies have demonstrated that NF- $\kappa \mathrm{B}$ activation also controls anti-inflammatory pathways, especially in macrophages [41]. When NF$\kappa \mathrm{B}$ signaling is repressed particularly in TAMs, they get to cytotoxic to tumor cells and switch to a "classically" activated phenotype [9]. PDTC, as an inhibitor of NF- $\kappa \mathrm{B}$ pathway, could enhance macrophages differentiation into pro-inflammatory M1 phenotype [42]. In our study, PDTC up-regulated the expression of $\operatorname{SIRP} \alpha$ and influenced the polarization of macrophages. Moreover, overexpression of SIRP $\alpha$ was reported to negatively modulate nuclear factor NF- $\kappa$ B signaling [23]. Inhibition of NF- $\kappa$ B pathway promotes M1-like phenotype in TAMs considering that improved tumoricidal activity is connected with M1 characteristics $[43,44]$. Since NF- $\kappa$ B is a vital transcription factor in immune response against tumor, this result might uncover that the tumoricidal activity of SIRP $\alpha-K D$ macrophages may be diminished as well. Therefore, SIRP $\alpha$ might regulate $\mathrm{NF}-\kappa \mathrm{B}$ signaling to switch the phenotype of macrophages, which could be a novel target by increasing macrophages tumoricidal activity.

\section{MATERIALS AND METHODS}

\section{Patients and samples}

Incisional biopsy samples from 20 clinically diagnosed OLK $(n=10)$ and OSCC $(n=10)$ were sent for histological confirmation according to the classical histopathological features. Five normal oral mucosa (NOM) samples obtained during third molar removal were used as negative controls in this study. All samples were obtained from the Department of Oral Medicine, School and Hospital of Stomatology, Wuhan University. For subgroup analysis, OLK samples were divided into OLK with low-risk dysplasia (LR-OLK) and OLK with highrisk dysplasia (HR-OLK) according to the scheme of the World Health Organization (2005) [45]. The characteristics of patients were showed in Table 1. Informed consent was obtained from each patient and normal control, and whole procedures were approved by the Ethical Committee of Hospital of Stomatology, Wuhan University.

\section{Immunohistochemistry}

Concentrations of primary antibodies were used for monoclonal mouse anti-human CD68 1:400, monoclonal mouse anti-human CD163 1:400, and for polyclonal rabbit anti-human SIRP $\alpha$ 1:50, and all were obtained from Abcam biotechnology. Paraffin sections were dewaxed and rehydrated through a series of xylene, graded alcohol and water immersion steps. The deparaffinized and hydrated slides were treated with $3 \% \mathrm{H}_{2} \mathrm{O}_{2}$ at $37^{\circ} \mathrm{C}$ for 20 min to block endogenous peroxidase activity and then washed with phosphate buffered saline (PBS). Slides were treated with $5 \%$ normal goat serum for 30 min to block non-specific binding, and then incubated with primary antibodies at $4{ }^{\circ} \mathrm{C}$ overnight as suggested by the product instruction. After washing with PBS, they were incubated with biotinylated goat anti-mouse or goat anti-rabbit IgG antibody (SP Kit; Zhongshan Golden Bridge Ltd., Beijing, China) for $20 \mathrm{~min}$ and washed again with PBS. They were treated with 3'3-diaminobenzidine tetrachloride (DAB) for $3 \mathrm{~min}$, and counter-stained with Mayer's hematoxylin, dehydrated and mounted with a glass coverslip and xylene-based mountant. Negative controls were incubated with PBS instead of primary antibodies.

\section{Double-labelling immunofluorescence}

Double-labelling immunofluorescence was used to define expressing of SIRP $\alpha$ in OLK and OSCC. Five control, five OLK and five OSCC specimens were randomly selected from the previously cut sections and were labelled with a primary SIRP $\alpha$ antibody (as above) and anti-CD163 antibody or anti-CD68 antibody. The secondary antibodies were Alexa Fluor 488 goat anti-mouse IgG and Alexa Fluor 596 goat anti-rabbit IgG (Zhongshan Golden Bridge Ltd., Beijing, China), and both used at diluted solution 1:100 for $60 \mathrm{~min}$ at room temperature.

\section{Evaluation and cell counting}

Slides were interpreted by two investigators who were blind to clinical details. Cell cytoplasm and 
Table 1: The characteristics of patients

\begin{tabular}{|c|c|c|c|c|c|c|}
\hline Sample & Gender & Age & Location & $\begin{array}{c}\text { Pathological } \\
\text { grade }\end{array}$ & Tobacco & Alcohol \\
\hline K1 & M & 60 & tongue & HR-OLK & $\mathrm{N}$ & $\mathrm{N}$ \\
\hline K2 & M & 57 & tongue & HR-OLK & $\mathrm{N}$ & Y \\
\hline K3 & $\mathrm{F}$ & 58 & tongue & HR-OLK & $\mathrm{N}$ & $\mathrm{N}$ \\
\hline K4 & M & 48 & bucca & LR-OLK & Y & Y \\
\hline K5 & M & 47 & bucca & HR-OLK & $\mathrm{N}$ & $\mathrm{Y}$ \\
\hline K6 & M & 75 & tongue & HR-OLK & $\mathrm{N}$ & $\mathrm{N}$ \\
\hline K7 & $\mathrm{F}$ & 71 & tongue & LR-OLK & $\mathrm{N}$ & $\mathrm{N}$ \\
\hline K8 & M & 75 & bucca & LR-OLK & $\mathrm{N}$ & $\mathrm{N}$ \\
\hline K9 & M & 48 & tongue & LR-OLK & $\mathrm{N}$ & Y \\
\hline K10 & F & 45 & tongue & LR-OLK & $\mathrm{N}$ & $\mathrm{N}$ \\
\hline $\mathrm{C} 1$ & F & 60 & tongue & OSCC & $\mathrm{N}$ & $\mathrm{N}$ \\
\hline $\mathrm{C} 2$ & M & 46 & tongue & OSCC & $\mathrm{Y}$ & $\mathrm{N}$ \\
\hline $\mathrm{C} 3$ & F & 45 & tongue & OSCC & $\mathrm{N}$ & $\mathrm{N}$ \\
\hline $\mathrm{C} 4$ & $\mathrm{~F}$ & 57 & bucca & OSCC & $\mathrm{N}$ & $\mathrm{N}$ \\
\hline $\mathrm{C} 5$ & M & 75 & lip & OSCC & $\mathrm{N}$ & $\mathrm{N}$ \\
\hline C6 & $\mathrm{F}$ & 33 & tongue & OSCC & $\mathrm{N}$ & $\mathrm{N}$ \\
\hline $\mathrm{C} 7$ & $\mathrm{M}$ & 76 & lip & OSCC & $\mathrm{N}$ & $\mathrm{N}$ \\
\hline $\mathrm{C} 8$ & M & 48 & tongue & OSCC & Y & Y \\
\hline C9 & F & 78 & bucca & OSCC & $\mathrm{N}$ & $\mathrm{N}$ \\
\hline $\mathrm{C} 10$ & M & 50 & bucca & OSCC & $\mathrm{N}$ & Y \\
\hline N1 & $\mathrm{F}$ & 45 & gingiva & NOM & $\mathrm{N}$ & $\mathrm{N}$ \\
\hline $\mathrm{N} 2$ & M & 23 & gingiva & NOM & $\mathrm{N}$ & $\mathrm{N}$ \\
\hline N3 & $\mathrm{F}$ & 53 & lip & NOM & $\mathrm{Y}$ & $\mathrm{N}$ \\
\hline N4 & F & 16 & lip & $\mathrm{NOM}$ & $\mathrm{N}$ & $\mathrm{N}$ \\
\hline N5 & $\mathrm{F}$ & 56 & lip & NOM & $\mathrm{N}$ & $\mathrm{N}$ \\
\hline N6 & $\mathrm{M}$ & 18 & bucca & NOM & $\mathrm{N}$ & $\mathrm{N}$ \\
\hline N7 & $\mathrm{M}$ & 61 & tongue & NOM & $\mathrm{N}$ & $\mathrm{N}$ \\
\hline N8 & $\mathrm{F}$ & 49 & lip & $\mathrm{NOM}$ & $\mathrm{N}$ & $\mathrm{N}$ \\
\hline N9 & $\mathrm{F}$ & 21 & tongue & NOM & $\mathrm{N}$ & $\mathrm{N}$ \\
\hline N10 & $\mathrm{M}$ & 40 & lip & $\mathrm{NOM}$ & $\mathrm{N}$ & $\mathrm{Y}$ \\
\hline
\end{tabular}

Gender F: female; Gender M: man; OLK: oral leukoplakia; OSCC: oral squamous cells carcinoma; NOM: normal oral mucosa; N: no; Y: yes.

membrane localization of SIRP $\alpha, \mathrm{CD} 68$, and CD163 were considered as positive results. In each slide, three staining areas throughout the epithelium were selected randomly, and positive cells were counted in high-power fields (Olympus Optical Co Ltd., Tokyo, Japan). Percentage of positive cells per field of SIRP $\alpha, \mathrm{CD} 68$ or CD163 was calculated and the mean percentage of positive cells per field of each case was represented by the average of three areas of each slide.

\section{Cell line culture}

THP-1 cells are a human leukemia monocytic cell line extensively used to study the modulation of monocytes and macrophages [46]. THP-1 cells in the monocyte state can be differentiated into a macrophagelike phenotype stimulated by phorbol-12-myristate13-acetate (PMA) [47]. THP-1 cells were cultured in RPMI 1640 medium (Invitrogen, Carlsbad, CA, USA) 
supplemented with $10 \% \mathrm{FBS}, 100$ units $/ \mathrm{ml}$, and 100 $\mathrm{ng} / \mathrm{ml}$ streptomycin. Cal-27 cell line was cultured in DMEM supplemented, and SCC9 cell line was cultured in DMEM F-12, all with $10 \%$ bovine serum and 1 $\%$ gentamycin. All cell lines were incubated at $37{ }^{\circ} \mathrm{C}$ under a humidified $5 \% \mathrm{CO}_{2}$ and $95 \%$ air atmosphere. The conditioned media of Cal-27 and SCC 9 cell lines were extracted and stored at $4{ }^{\circ} \mathrm{C}$ after cell line was grown until 89-90\% confluent. The cells were free of mycoplasma contaminated during the study period until now.

\section{Cells immunofluorescence}

To quantitate the effect of cancer cells on macrophage, an in vitro indirect co-culture system was employed. Briefly, $2 \times 10^{5}$ THP- 1 cells/ml RPMI were seeded in 6-well plates and stimulated by $100 \mathrm{nM}$ PMA for $24 \mathrm{~h}$, to induce the differentiation of cell into macrophages. After washed by PBS for three times, the conditioned media of Cal-27 and SCC9 cell lines were added to each well, and incubated for 1 day. Cells were stained by using rabbit polyclonal antibody to SIRP $\alpha$ and mouse monoclonal antibody to CD68 (Abcam) at appropriate dilutions, followed by incubation with $\mathrm{Cy} 3-$ conjugated anti-rabbit IgG antibodies and Cy5-conjugated anti-mouse IgG antibodies (Zhongshan Golden Bridge Ltd., Beijing, China), and observed by a fluorescent microscope (Leica Microsystems, German).

\section{Flow cytometric analysis}

$1 \times 10^{6} \mathrm{THP}-1$ cells/well in triplicates were placed in wells of two plates. Cells were stimulated with PMA for $24 \mathrm{~h}$. After washed by PBS for three times, conditioned media of Cal-27 and SCC-9 cell lines were added and incubated for $0,1,3,5,7,9$ days, respectively. After cultured day, the supernatant was discarded and the cells were washed twice in PBS. The cells were resuspended in $100 \mu \mathrm{L}$ of PBS with SIRP $\alpha$ antibody and CD163 antibody or with a control in PBS containing $0.5 \%(w / v) ~ B S A$, and were incubated for $30 \mathrm{~min}$ at $4{ }^{\circ} \mathrm{C}$. Cells were analyzed on a fluorescent activated cell sorter (BD Biosciences, San Jose, CA). APC-CD163 and PE-SIRP $\alpha$ antibodies were used and purchased from Biolegend (San Diego, CA). After incubation, the tubes were centrifuged at $300 \times \mathrm{g}$ at $37^{\circ} \mathrm{C}$ for $5 \mathrm{~min}$ and washed three times in PBS with centrifugation at $300 \times \mathrm{g}$ at $37^{\circ} \mathrm{C}$ for 5 min between each wash. PBS from the third wash was left in the tubes for flow cytometry. Results were presented using FlowJo (FlowJo LLC, Ashland,USA).

\section{Co-culture assay}

6-well transwell plate with a polycarbonate filter membrane of $0.4 \mu \mathrm{m}$ pore size (Corning, Acton, MA,
USA) was used to establish co-culture system. The upper compartment of the transwell chamber was seeded with THP- 1 cells at a density of $1 \times 10^{5}$ in $200 \mu$ of RPMI 1640 medium, and the lower chamber was seeded with Cal-27 cells at a density of $1 \times 10^{4}$ in $500 \mu \mathrm{l}$ of DMED medium.

For subgroup analysis, according to different stimulation, co-culture groups were divided into PMA group, Cal-27 group, si-KD group, PDTC group, LPS group, IL-4 group, and hypoxia group. THP-1 cells in all groups were induced to macrophages by $100 \mathrm{nM}$ PMA. For PMA group, macrophages were co-cultured with DMEM medium. For Cal-27 group, THP-1 cells were co-cultured with Cal-27 cells for $24 \mathrm{~h}$ and $48 \mathrm{~h}$ after stimulated by PMA. Macrophages in si-KD group were transfected with small interference RNA (siRNA) for $24 \mathrm{~h}$ and after transfection, macrophages were cocultured with Cal-27 for $24 \mathrm{~h}$ and $48 \mathrm{~h}$. For LPS group, macrophages were treated with $1 \mu \mathrm{g} / \mathrm{mL}$ LPS for $24 \mathrm{~h}$. For PDTC group, macrophages were treated with 50 $\mu \mathrm{mol} / \mathrm{mL}$ PDTC for $24 \mathrm{~h}$ and co-cultured with Cal-27 for $24 \mathrm{~h}$ and $48 \mathrm{~h}$. For IL-4 group, macrophages were treated with $10 \mu \mathrm{g} / \mathrm{mL} \mathrm{IL-4}$ for $24 \mathrm{~h}$. Co-culture with DMEM medium, macrophages in hypoxia group were incubated in a hypoxia incubator chamber which was flushed with $1 \% \mathrm{O}_{2}, 5 \% \mathrm{CO}_{2}$.

\section{siRNA transfection}

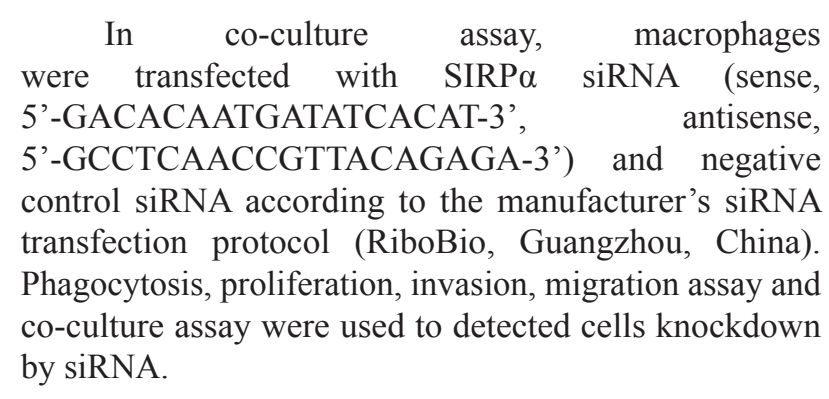

\section{Western blot analysis}

Cultured cells were washed immediately with ice-cold PBS and lysed by RIPA buffer containing PMSF (Beyotime Biotechnology, Shanghai, China) and phosphatase inhibitors (Beyotime Biotechnology). Whole cell lysates were collected after centrifugation at $12000 \mathrm{~g}$ for $15 \mathrm{~min}$ at $4{ }^{\circ} \mathrm{C}$, and protein concentration in the supernatants was determined by BCA assay kit (Beyotime Biotechnology). Equal amounts of protein (6 $\mu \mathrm{g} /$ lane) were loaded onto $12 \%$ SDS-polyacrylamide gels, subjected to electrophoresis and transferred to PVDF membranes (Millipore Boston, Massachusetts, USA). After blocking with $5 \%$ nonfat milk for $1 \mathrm{~h}$, membranes were incubated overnight at $4{ }^{\circ} \mathrm{C}$ with primary antibody anti-SIRP $\alpha$ (1:100; Santa Cruz Biotechnology), antip65 ${ }^{\mathrm{S} 536}$, and anti-phosphorylated-p65 ${ }^{\mathrm{S} 536}$ (1:1000; Cell signaling Technology). After three washes with TBST, 
Table 2: Primer sequence for RT-PCR

\begin{tabular}{ll}
\hline Gene & Primer \\
\hline \multirow{2}{*}{ CD68 } & FP 5'-TTGGGTGAGGCGGTTCAGCCAT-3' \\
& RP 5'-GTGCTCTCTGTAACCGTGGGTGT-3' \\
CD163 & FP 5'-ACATAGATCATGCATCTGTCATTTG-3' \\
& RP 5'-CATTCTCCTTGGAATCTCACTTCTA-3' \\
TNF $\alpha$ & FP 5'-TCTTCTCGAACCCCGAGTGA-3' \\
& RP 5'-CCTCTGATGGCACCACCAG-3' \\
TGF $\beta$ & FP 5'-GGGACTATCCACCTGCAAGA-3' \\
SIRP $\alpha$ & RP 5'-CCTCCTTGGCGTAGTAGTCG-3' \\
& FP 5'-GCCCACAGGGATGATGTGAA-3' \\
IL-6 & RP 5'-TGTGATATCATTTGTGTCCTGTGT-3' \\
& FP 5'-TACATCCTCGACGGCATCT-3' \\
IL-10 & RP 5'-ACCAGGCAAGTCTCCTCAT-3' \\
& FP 5'-TCAGAGAGGGGGTTAGACCTG-3' \\
& RP 5'-GAGTTGGTCCTGCCAGACTT-3'
\end{tabular}

membranes were then incubated with HRP-labelled secondary antibody for $1 \mathrm{~h}$ at room temperature. The protein bands were visualized using ECL reagent, and quantified by densitometry using Image J. $\beta$-actin was used as the internal loading control. Western blot experiments were repeated at least three times.

\section{Cell migration and invasion assay}

Cell migration was assessed by using the 24-well transwell plate with a polycarbonate filter membrane of $8 \mu \mathrm{m}$ pore size (Corning, Acton, MA, USA). The upper compartment of the transwell chamber was seeded with THP- 1 cells at a density of $1 \times 10^{5}$ in $200 \mu$ of serumfree medium, and the lower chamber was seeded with Cal-27 cells at a density of $1 \times 10^{4}$ in $500 \mu$ of DMED medium. For the cell migration assay, after $12 \mathrm{~h}$ and 24 $\mathrm{h}$ incubation, the medium was discarded and the filter membrane was fixed with $4 \%$ formaldehyde, stained with $0.1 \%$ crystal violet and examined under an inverted microscope to count migrated cells in 5 different fields. For the cell invasion assay, macrophages were seeded to the upper compartment of BD BioCoat Matrigel chambers (BD Biosciences, San Jose, CA, USA) at a cell density of $1 \times 10^{6}$ and incubated for $24 \mathrm{~h}$ and $48 \mathrm{~h}$. After incubation, the invaded cells on the lower surface were stained with $0.1 \%$ crystal violet and counted in 5 randomly selected fields. To detect the cell migration and invasion of Cal27 cells, the same experiment was applied and the upper chamber was seeded with Cal-27 cells while the lower chamber was seeded with THP-1 cells.

\section{RNA isolation and cDNA synthesis}

Total RNA from macrophages was extracted using TRIZOL reagent (Invitrogen, Burlington, ON,
USA) according to the manufacturer's instructions. Concentration and purity were determined by NanoDrop 1000 spectrophotometer (Thermo Fisher Scientific Inc, Dubuque, USA). RNA (1.0 $\mu \mathrm{g})$ was used as template for the synthesis of cDNA $(20 \mu \mathrm{l})$ with Oligo-dT and AMV reverse transcriptase (Takara, Japan).

\section{Real-time PCR}

RT reaction from $1 \mu \mathrm{g}$ RNA template was performed using PrimeScript ${ }^{\mathrm{TM}}$ RT Reagent Kit with gDNA Eraser (Takara, Japan) as manufacturer's instructions. Real-time PCR was done using SYBR $®$ Premix Ex Taq II (Applied Biosystems, Foster City, CA) and detected by ABI-Prism 7900 Sequence Detector (Applied Biosystems, Foster City, CA). The primers used were listed on the Table 2 and synthesized by Sangon Biotech (Sengon, Shanghai, China). The values were calculated applying the $2^{-\Delta \Delta \mathrm{Ct}}$ method. All real-time results were expressed as fold changes in mRNA expression compared to the control cells. All results were normalized to the expression of the housekeeping gene GAPDH in the PCR reactions.

\section{Cell proliferation assay}

THP-1 cells were seeded at a density of $2 \times 10^{3}$ cells per well in 96-well culture plates. The relative cell number of PMA group, PDTC group, and si-KD group were was then detected by cell counting kit-8 (CCK-8) assay (Dojin Laboratory, Kumamoto, Japan) according to the manufacturer's instructions. Briefly, $10 \mu \mathrm{L}$ of CCK-8 solution was added to each well during the last $2 \mathrm{~h}$ of culture at $37^{\circ} \mathrm{C}$, and absorbance in each well was measured at $450 \mathrm{~nm}$ using a 96-well multiscanner autoreader (Thermo Fisher Scientific, USA). 


\section{Neutral red uptake assay for macrophage phagocytosis}

The phagocytic ability of macrophage was measured by neutral red uptake. Cells in Cal-27, LPS, si-KD, and PDTC groups were cultured for $24 \mathrm{~h}, 100$ $\mu 1$ neutral red solutions was added and incubated for 30 min. The supernatant was discarded and the cells in 96well plates were washed with PBS twice to remove the neutral red that was not phagocytized by macrophages. Then cell lysate (ethanol and $0.01 \%$ acetic acid at the ratio of $1: 1,100 \mu \mathrm{l} /$ well) was added to lyse cells. After cells were incubated in room temperature overnight, the optical density at $540 \mathrm{~nm}$ was measured by multiscanner autoreader.

\section{Statistical analysis}

Data were analyzed by GraphPad Prism version 5.0 (Graphpad Software Inc., La Jolla, CA, USA). The relationship between clinicopathological parameters and oral dysplasia grade and expression of CD163, CD68, and SIRP $\alpha$ of macrophage were analyzed using the One-Way ANOVA. Comparison of mean values was performed with a Tukey test. Correlations between the various markers were tested using nonparametric Spearman's rank analysis. The One-Way ANOVA were used to evaluate the differences between experimental and control groups.

\section{CONCLUSION}

Our findings provide a new insight into the importance of SIRP $\alpha$ on macrophages in oral leukoplakia and oral cancer progression. In addition, SIRP $\alpha$ could be applied as an important modulator of the phenotype of macrophages in OSCC by targeting NF- $\kappa \mathrm{B}$. Therefore, SIRP $\alpha$ might be a potential target for oral cancer therapy.

\section{ACKNOWLEDGMENTS}

We apologize to colleagues whose primary research papers may not have been cited due to space constraints.

\section{CONFLICTS OF INTEREST}

The authors declare no conflict of interest.

\section{GRANT SUPPORT}

This work was supported by grants from Nonprofit Industry Research Specific Fund of National Health and Family Planning Commission of China (No. 201502018) and the National Natural Science Foundation of China (No. 81371147, No. 81170972) to Gang Zhou.

\section{REFERENCES}

1. Quan J, Johnson NW, Zhou G, Parsons PG, Boyle GM, Gao J. Potential molecular targets for inhibiting bone invasion by oral squamous cell carcinoma: a review of mechanisms. Cancer metastasis reviews. 2012; 31:209-219.

2. Gaitan-Cepeda LA, Peniche-Becerra AG, Quezada-Rivera D. Trends in frequency and prevalence of oral cancer and oral squamous cell carcinoma in Mexicans. A 20 years retrospective study. Medicina oral, patologia oral y cirugia bucal. 2011; 16:e1-5.

3. Hunter KD, Yeoman CM. An update on the clinical pathology of oral precancer and cancer. Dental update. 2013; 40:120-122, 125-126.

4. Hanahan D, Weinberg RA. Hallmarks of cancer: the next generation. Cell. 2011; 144:646-674.

5. Liu Y, Cao X. The origin and function of tumor-associated macrophages. Cellular \& molecular immunology. 2015; $12: 1-4$.

6. Mantovani A, Garlanda C. Platelet-macrophage partnership in innate immunity and inflammation. Nature immunology. $2013 ; 14: 768-770$.

7. Davies LC, Taylor PR. Tissue-resident macrophages: then and now. Immunology. 2015; 144:541-548.

8. Glass CK, Natoli G. Molecular control of activation and priming in macrophages. Nature immunology. 2015; 17:26-33.

9. Hagemann T, Lawrence T, McNeish I, Charles KA, Kulbe H, Thompson RG, Robinson SC, Balkwill FR. "Re-educating" tumor-associated macrophages by targeting NF-kappaB. The Journal of experimental medicine. 2008; 205:1261-1268.

10. Costa NL, Valadares MC, Souza PP, Mendonca EF, Oliveira JC, Silva TA, Batista AC. Tumor-associated macrophages and the profile of inflammatory cytokines in oral squamous cell carcinoma. Oral oncology. 2013; 49:216-223.

11. Postler TS, Ghosh S. Bridging the Gap: A Regulator of NF-kappaB Linking Inflammation and Cancer. Journal of oral biosciences. 2015; 57:143-147.

12. Connelly L, Barham W, Onishko HM, Chen L, Sherrill TP, Zabuawala T, Ostrowski MC, Blackwell TS, Yull FE. NF-kappaB activation within macrophages leads to an anti-tumor phenotype in a mammary tumor lung metastasis model. Breast cancer research. 2011; 13:R83.

13. Li E, Xu Z, Zhao H, Sun Z, Wang L, Guo Z, Zhao Y, Gao $Z$, Wang Q. Macrophages promote benzopyrene-induced tumor transformation of human bronchial epithelial cells by activation of NF-kappaB and STAT3 signaling in a bionic airway chip culture and in animal models. Oncotarget. 2015; 6:8900-8913. doi: 10.18632/oncotarget.3561.

14. Zhang Q, Cai DJ, Li B. Ovarian cancer stem-like cells elicit the polarization of M2 macrophages. Molecular medicine reports. 2015; 11:4685-4693. 
15. El-Rouby DH. Association of macrophages with angiogenesis in oral verrucous and squamous cell carcinomas. Journal of oral pathology \& medicine. 2010; 39:559-564.

16. Ni YH, Ding L, Huang XF, Dong YC, Hu QG, Hou YY. Microlocalization of CD68+ tumor-associated macrophages in tumor stroma correlated with poor clinical outcomes in oral squamous cell carcinoma patients. Tumour biology. 2015; 36:5291-5298.

17. Chiu KC, Lee CH, Liu SY, Chou YT, Huang RY, Huang SM, Shieh YS. Polarization of tumor-associated macrophages and Gas6/Axl signaling in oral squamous cell carcinoma. Oral oncology. 2015; 51:683-689.

18. Weber M, Buttner-Herold M, Hyckel P, Moebius P, Distel L, Ries J, Amann K, Neukam FW, Wehrhan F. Small oral squamous cell carcinomas with nodal lymphogenic metastasis show increased infiltration of M2 polarized macrophages--an immunohistochemical analysis. Journal of cranio-maxillo-facial surgery. 2014; 42:1087-1094.

19. Lu CF, Huang CS, Tjiu JW, Chiang CP. Infiltrating macrophage count: a significant predictor for the progression and prognosis of oral squamous cell carcinomas in Taiwan. Head \& neck. 2010; 32:18-25.

20. Murata Y, Kotani T, Ohnishi H, Matozaki T. The CD47SIRPalpha signalling system: its physiological roles and therapeutic application. Journal of biochemistry. 2014; 155:335-344.

21. Barclay AN, Van den Berg TK. The interaction between signal regulatory protein alpha (SIRPalpha) and CD47: structure, function, and therapeutic target. Annual review of immunology. 2014; 32:25-50.

22. Gautam PK, Acharya A. Suppressed expression of homotypic multinucleation, extracellular domains of CD172alpha (SIRP-alpha) and CD47 (IAP) receptors in TAMs upregulated by Hsp70-peptide complex in Dalton's lymphoma. Scandinavian journal of immunology. 2014; 80:22-35.

23. Ho JM, Danska JS, Wang JC. Targeting SIRPalpha in cancer. Oncoimmunology. 2013; 2:e23081.

24. Pan YF, Tan YX, Wang M, Zhang J, Zhang B, Yang C, Ding ZW, Dong LW, Wang HY. Signal regulatory protein alpha is associated with tumor-polarized macrophages phenotype switch and plays a pivotal role in tumor progression. Hepatology. 2013; 58:680-691.

25. Hu W, Li X, Zhang C, Yang Y, Jiang J, Wu C. Tumorassociated macrophages in cancers. Clinical \& translational oncology. 2016; 18:251-258.

26. Helm O, Held-Feindt J, Grage-Griebenow E, Reiling $\mathrm{N}$, Ungefroren H, Vogel I, Kruger U, Becker T, Ebsen M, Rocken C, Kabelitz D, Schafer H, Sebens S. Tumor-associated macrophages exhibit pro- and antiinflammatory properties by which they impact on pancreatic tumorigenesis. International journal of cancer. 2014; 135:843-861.
27. Kubler K, Ayub TH, Weber SK, Zivanovic O, Abramian A, Keyver-Paik MD, Mallmann MR, Kaiser C, Serce NB, Kuhn W, Rudlowski C. Prognostic significance of tumorassociated macrophages in endometrial adenocarcinoma. Gynecologic oncology. 2014; 135:176-183.

28. Fujii N, Shomori K, Shiomi T, Nakabayashi M, Takeda C, Ryoke K, Ito H. Cancer-associated fibroblasts and CD163positive macrophages in oral squamous cell carcinoma: their clinicopathological and prognostic significance. Journal of oral pathology \& medicine. 2012; 41:444-451.

29. Mori K, Hiroi M, Shimada J, Ohmori Y. Infiltration of $\mathrm{m} 2$ tumor-associated macrophages in oral squamous cell carcinoma correlates with tumor malignancy. Cancers. 2011; 3:3726-3739.

30. Mori K, Haraguchi S, Hiori M, Shimada J, Ohmori Y. Tumor-associated macrophages in oral premalignant lesions coexpress CD163 and STAT1 in a Th1-dominated microenvironment. BMC cancer. 2015; 15:573.

31. Chao MP, Weissman IL, Majeti R. The CD47-SIRPalpha pathway in cancer immune evasion and potential therapeutic implications. Current opinion in immunology. 2012; 24:225-232.

32. Yoshida K, Tsujimoto H, Matsumura K, Kinoshita M, Takahata R, Matsumoto Y, Hiraki S, Ono S, Seki S, Yamamoto J, Hase K. CD47 is an adverse prognostic factor and a therapeutic target in gastric cancer. Cancer medicine. 2015; 4:1322-1333.

33. Xiao Z, Chung H, Banan B, Manning PT, Ott KC, Lin S, Capoccia BJ, Subramanian V, Hiebsch RR, Upadhya GA, Mohanakumar T, Frazier WA, Lin Y, Chapman WC. Antibody mediated therapy targeting CD47 inhibits tumor progression of hepatocellular carcinoma. Cancer letters. 2015; 360:302-309.

34. McCracken MN, Cha AC, Weissman IL. Molecular Pathways: Activating T Cells after Cancer Cell Phagocytosis from Blockade of CD47 "Don't Eat Me" Signals. Clinical cancer research. 2015; 21:3597-3601.

35. Vonderheide RH. CD47 blockade as another immune checkpoint therapy for cancer. Nature medicine. 2015; 21:1122-1123.

36. Van Overmeire E, Laoui D, Keirsse J, Van Ginderachter JA. Hypoxia and tumor-associated macrophages: A deadly alliance in support of tumor progression. Oncoimmunology. 2014; 3:e27561.

37. Nakamura R, Sene A, Santeford A, Gdoura A, Kubota S, Zapata N, Apte RS. IL10-driven STAT3 signalling in senescent macrophages promotes pathological eye angiogenesis. Nature communications. 2015; 6:7847.

38. Kratochvill F, Neale G, Haverkamp JM, Van de Velde LA, Smith AM, Kawauchi D, McEvoy J, Roussel MF, Dyer MA, Qualls JE, Murray PJ. TNF Counterbalances the Emergence of M2 Tumor Macrophages. Cell reports. 2015; 12:1902-1914. 
39. Intayoung P, Limtrakul P, Yodkeeree S. Antiinflammatory Activities of Crebanine by Inhibition of NF-kappaB and AP-1 Activation through Suppressing MAPKs and Akt Signaling in LPS-Induced RAW264.7 Macrophages. Biological \& pharmaceutical bulletin. 2016; 39:54-61.

40. Mancino A, Lawrence T. Nuclear factor-kappaB and tumorassociated macrophages. Clinical cancer research. 2010; 16:784-789.

41. Rego SL, Helms RS, Dreau D. Breast tumor cell TACEshed MCSF promotes pro-angiogenic macrophages through NF-kappaB signaling. Angiogenesis. 2014; 17:573-585.

42. Jin X, Yao T, Zhou Z, Zhu J, Zhang S, Hu W, Shen C. Advanced Glycation End Products Enhance Macrophages Polarization into M1 Phenotype through Activating RAGE/ NF-kappaB Pathway. BioMed research international. 2015; 2015:732450.

43. Wang Q, Cheng F, Ma TT, Xiong HY, Li ZW, Xie CL, Liu CY, Tu ZG. Interleukin-12 inhibits the hepatocellular carcinoma growth by inducing macrophage polarization to the M1-like phenotype through downregulation of Stat-3. Molecular and cellular biochemistry. 2016.

44. Luo M, Liang X, Luo ST, Wei XW, Liu T, Ren J, Ma CC, Yang YH, Wang BL, Liu L, Song XR, He ZY, Wei YQ. Folate-Modified Lipoplexes Delivering the Interleukin-12 Gene for Targeting Colon Cancer Immunogene Therapy. Journal of biomedical nanotechnology. 2015; 11:2011-2023.

45. Thompson L. World Health Organization classification of tumours: pathology and genetics of head and neck tumours. Ear, nose, \& throat journal. 2006; 85:74.

46. Chanput W, Mes JJ, Wichers HJ. THP-1 cell line: an in vitro cell model for immune modulation approach. International immunopharmacology. 2014; 23:37-45.

47. Phillips RJ, Lutz M, Premack B. Differential signaling mechanisms regulate expression of $\mathrm{CC}$ chemokine receptor-2 during monocyte maturation. Journal of inflammation. 2005; 2:14. 